\title{
ETNOGRAFÍA HISTÓRICA DE LA PLANTA BALLENERA EN ISLA GUAFO [1921-1937]
}

DANIEL QUIROZ

\section{RESUMEN}

La caza moderna de ballenas comienza en Chile en la primera década del siglo XX. Desde esa fecha se construyeron ocho plantas industriales costeras, destinadas al procesamiento de las ballenas, localizadas entre Punta Arenas por el sur e Iquique por el norte. Una de las menos conocidas es la instalada en caleta Samuel, isla Guafo, construida por la Sociedad Pescadores de Chile y Noruega en la temporada 1922-1923. En este trabajo tratamos de reconstruir la historia de la planta, su funcionamiento y sus trabajadores. La planta fue una verdadera escuela ballenera para muchos de los habitantes del sur de Chiloé, quiénes luego traspasaron esos conocimientos y habilidades a los nuevos balleneros de Quintay y Bajo Molle. Guafo.

PALABRAS CLAVE: caza de ballenas, estación ballenera costera, etnografía histórica, isla

\section{HISTORICAL ETHNOGRAPHY OF THE SHORE WHALING STATION AT GUAFO ISLAND [1921-1937]}

\begin{abstract}
Modern whaling began in Chile in the first decade of the twentieth century. Since then, eight shore industrial stations for processing whales were built, located between Punta Arenas and Iquique. One of the least known, built by Sociedad Pescadores Chile y Noruega in the 1922-1923 seasons, is installed in Caleta Samuel, Guafo Island. In this paper we try to reconstruct the history of the station, its operations and workers. The Guafo station, was a real "whaling school" for the inhabitants of southern Chiloé, who then transferred their knowledge and skills to new whalers from Quintay and Bajo Molle.
\end{abstract}

KEY WORDS: whaling, shore whaling station, historical ethnography, Guafo Island 


\section{INTRODUCCIÓN}

La caza de ballenas con propósitos comerciales, definida como la matanza intencional de grandes cetáceos para obtener productos económicamente útiles (Reeves \& Smith, 2006: 82), comienza en el mundo occidental a partir del siglo X o XI de nuestra era, cuando grupos de pescadores vascos capturan la ballena franca en el Golfo de Vizcaya para obtener grasa, aceite, carne y barbas, que vendían por toda Europa (Aguilar, 1986; Azpiazu, 2000). Los vascos habrian aprendido sus técnicas balleneras de los normandos, quienes a su vez las habrian obtenido de los vikingos de Noruega e Islandia (du Pasquier, 2000). Los balleneros vascos, en naos y pinazas, seguirán a sus presas por todo el Atlántico Norte, desde Cantabria, Asturias y Galicia hasta Irlanda, Islandia y Terranova (Azpiazu, 2000). Los holandeses, ingleses, alemanes, daneses, escoceses $y$, finalmente, los norteamericanos seguirán los pasos de los vascos (Hacquebord, 2003), recorriendo los diversos mares del planeta, incluyendo, desde finales del siglo XVIII, el Océano Pacífico (Baker \& Clapham, 2002, Davis et al., 1997). Este proceso de universalización se intensifica cuando se conocen las rutas de migración de los cetáceos en el Pacífico Sur (Ellis, 1991) y se descubre la presencia de una gran cantidad de ballenas en aguas antárticas (Tønnesen \& Johnsen, 1982). La cacería de ballenas se transforma así en una actividad completamente "globalizada", es decir, desarrollada prácticamente en todos los océanos del mundo (Basberg, 2004).

Los norteamericanos introdujeron en el siglo XVIII una innovación que transformará la caza de ballenas en el mundo. Consistía en la transferencia del proceso de elaboración del aceite desde instalaciones costeras a la cubierta de un buque, donde había grandes hornos de ladrillo (Davis et al., 1997). Esta innovación mejoró la calidad del aceite al procesar la grasa de inmediato y permitió realizar expediciones de larga distancia que duraban entre tres y cuatro años (Ellis, 1991). Tal vez uno de los períodos de mayor auge de la industria ballenera mundial corresponde a la primera mitad del siglo XIX cuando una gran cantidad de veleros de distintas nacionalidades, en especial norteamericanos, pero también ingleses, franceses y alemanes, recorrerán los diversos mares del planeta en busca de ballenas, tocando las costas de Chile en lugares como Ancud, Talcahuano, Valparaíso y Coquimbo (Pereira Salas, 1971). Esta modalidad es probablemente la más conocida para el público, difundida por esa magistral novela Moby Dick, escrita por Herman Melville e inspirada por situaciones reales ocurridas en los alrededores de la isla Mocha, en Chile (Cartes, 2009).

La segunda gran transformación ocurrirá en el norte de Noruega durante la segunda mitad del siglo XIX (Reeves \& Smith, 2006, Basberg, 2008), cuando se comienzan a utilizar buques a vapor especialmente construidos para la caza de ballenas. El buque ideal debía ser rápido, poderoso, maniobrable y virtualmente imposible de hundirse (Davis et al., 1997: 500). Los buques usaban para la matanza un arpón explosivo lanzado desde un cañón montado en la proa (Brown, 1976: 25). El hecho de contar con barcos rápidos permitió la captura de todo tipo de ballenas, incluidos los grandes rorcuales, como la ballena azul y la de aleta.

Las carcasas de los cetáceos eran procesadas en plantas terrestres para producir aceite y abono (Tønnesen \& Johnsen, 1982, pp. 39-40). El proceso productivo desarrollado en una planta ballenera terrestre puede ser descrito, al mismo tiempo, como algo muy simple y muy complejo: era simple ya que hay unas pocas lineas de producción, que terminan en dos o tres productos principales, aceite y harina o guano de ballenas pero era bastante complejo en sus detalles técnicos, representados por numerosas y diversas cocinerías, estanques, separadores, válvulas, cintas transportadoras y tuberías, que iban en todas las direcciones (Basberg, 2004: 83).

Todo el proceso comenzaba con la llegada de la ballena a la planta. La ballena era amarrada con una línea al huinche e izada a la rampa y luego a la plataforma de descuartizamiento. Allí se separaba el tocino, la carne y los huesos que iban, cada uno, a sus propias unidades de cocción o "cocinerías". De las tres cocinerías se obtenía aceite y una mezcla de líquidos y sólidos que eran enviados a plantas de purificación. Los residuos sólidos eran enviados a la planta de harina o de guano (Basberg, op.cit., pp. 83-84). Estas operaciones forman parte de 


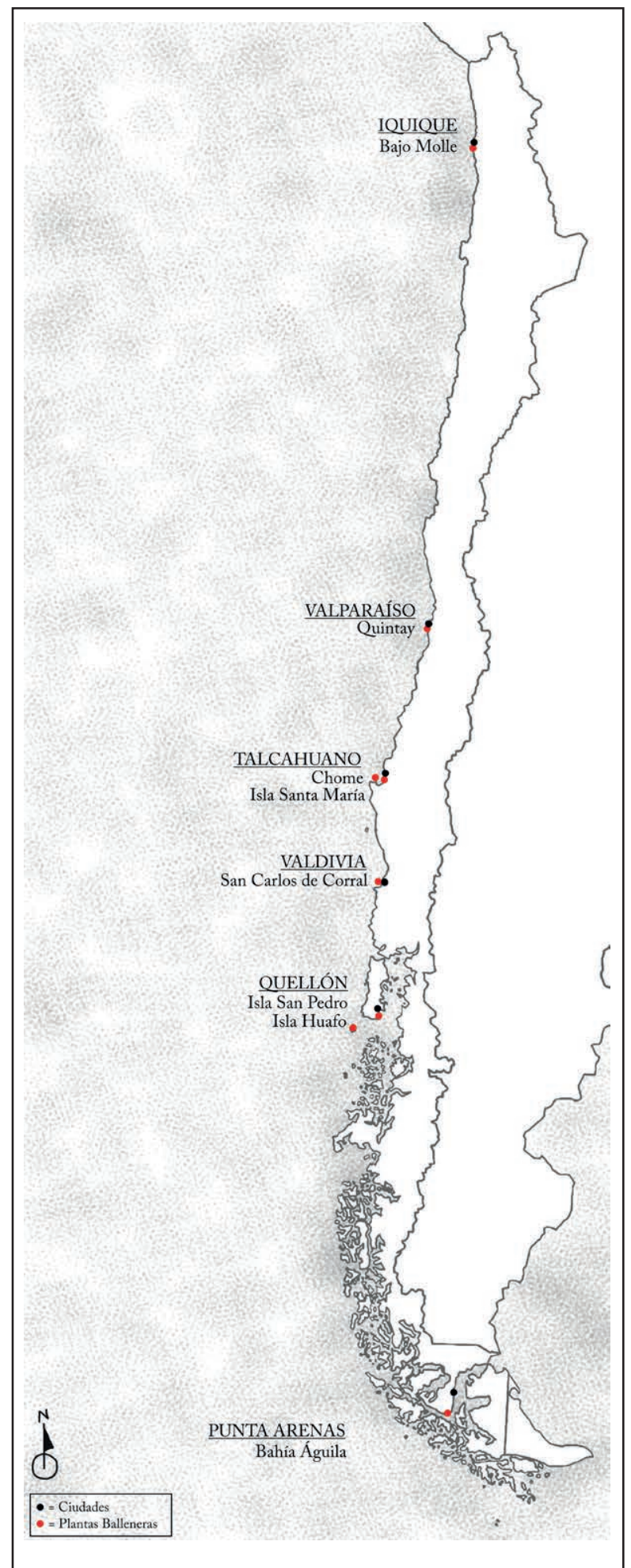

Fig. 1 Mapa con la ubicación de las plantas balleneras en Chile [Dibujo Paula de la Fuente] lo que se ha denominado tradición ballenera noruega o caza moderna de ballenas (Pastene \& Quiroz, 2010).

En Chile se construyeron ocho plantas industriales terrestres, destinadas al procesamiento de las ballenas, localizadas entre Punta Arenas por el sur e Iquique por el norte (Fig. 1). La primera y la más meridional fue la de Bahía Águila, situada a $60 \mathrm{~km}$ al oeste de Punta Arenas. Esta planta fue construida en 1905 por la Sociedad De Bruyne, Andresen y Cia., empresa que dará origen en 1906 a la Sociedad Ballenera de Magallanes (Nicholls, 2010; Duque, 2012). En 1906 la Sociedad Ballenera y Pescadora de Valdivia levanta la planta de San Carlos de Corral, Valdivia (Quiroz, 2010a). En 1909 la Ballenera del Pacífico construye la planta Normandía, en Isla San Pedro, al sur de Quellón, Chiloé (Quiroz, 2010b). La Sociedad Pescadores de Chile y Noruega levanta entre 1922 y 1923 una planta en Caleta Samuel, Isla Guafo, al sur de la isla grande de Chiloé (Quiroz, 2010a). En la década de 1930 la Sociedad Comercial Juan Macaya e Hijos, construye una pequeña planta en Puerto Macaya, Isla Santa María, en el golfo de Arauco (Carreño \& Espinoza, 2012). La Compañía Industrial S.A, inaugura en 1943 su planta de Quintay, al sur de Valparaíso, y en 1956 la de Bajo Molle, al sur de Iquique. En 1951 la Sociedad Comercial Macaya Hermanos, sucesora de Juan Macaya e Hijos, cierra la antigua planta de la isla Santa María y construye una planta moderna en Chome, al sur de Talcahuano (Carreño \& Espinoza, 2012)

En este trabajo nos interesa entregar la información que hemos reunido, fragmentaria y muy variada, sobre la planta ballenera instalada en Caleta Samuel, isla Guafo ${ }^{1}$, una de las menos conocidas. Queremos mostrar su historia, su funcionamiento y el mundo de sus trabajadores. Resulta importante destacar que la planta fue una verdadera "escuela ballenera" para muchos habitantes del sur de Chiloé, quiénes luego traspasaron esos conocimientos y habilidades a los nuevos balleneros de Quintay y Bajo Molle (de la

En este trabajo hemos utilizado la grafía Guafo para referirnos al nombre de la isla en vez de Huafo. Sin embargo, hemos conservado la grafía Huafo cuando se usa en una cita documental. 
Fuente \& Quiroz, 2011).

\section{La etnografía histórica}

La caza de ballenas constituye hoy, en nuestro país (Martinic, 1973, 1977, 2004; Guzmán, 2006; Sepúlveda, 2008), un conjunto de eventos pasados, es decir, eventos que no pueden ser observados directamente, y la posibilidad de desarrollar una etnografía de eventos pasados coloca al investigador frente al dilema de apelar a técnicas de recolección de datos más ligadas a otras disciplinas, como la historia (Gil, 2010: 250). La información sobre estos "eventos pasados" está almacenada en "archivos", espacios donde el historiador desarrolla su "trabajo de campo" y elabora sus principales herramientas analíticas (O’Dell \& Willim, 2011). La etnografía de "eventos pasados", llamada también etnografía histórica (Wietschorke, 2010), se basa en la habilidad de sus practicantes en examinar lo ignorado o llamar la atención sobre aquellas áreas de la vida que no han sido cuestionadas o han pasado inadvertidas (Wilson, 2012:16). La etnografía contiene muchos métodos diversos, todos basados, de alguna manera, en textos de distinta naturaleza. ¿Es posible, para los etnógrafos del pasado [lograr] describir y comprender un mundo perdido (Lennartsson, 2011:107-109). La etnografía es una disciplina narrativa [y] la etnografía histórica no es una excepción (Lennartsson, 2012:90).

La antropología ha trabajado en los archivos desde hace mucho tiempo y la larga, y a veces conflictiva, relación entre antropología e historia nos entrega un conjunto de ideas y conceptos que debemos entenderlos como una oportunidad epistemológica, una fuente desde donde poder generar nuevos conocimientos. La imposibilidad de observar la caza de ballenas directamente no impide visitar los lugares donde se produjo, contemplar sus "ruinas", conversar con la gente que participó de ella y buscar en bibliotecas y archivos, datos y noticias sobre las distintas facetas de su práctica. Los materiales son entonces un conjunto de "recortes", "recuerdos" y "ruinas" que debemos integrar en una etnografía histórica que entregue una narración plausible sobre la historia, características y funcionamiento de la planta ballenera de Guafo.

Revisamos acuciosamente las publicaciones relacionadas con la caza de ballenas en las costas de Chile y obtuvimos datos fragmentarios sobre el proceso de construcción, sus operaciones y posterior desmantelamiento. Buscamos documentos inéditos. Revisamos sistemáticamente en Valdivia el Archivo del Conservador de Bienes Raíces de esa ciudad. Consultamos en el Archivo de la Administración del Archivo Nacional algunos fondos específicos de Notarios y Conservadores de Bienes Raíces de Santiago y también los Decretos del Ministerio de Hacienda que autorizaban el funcionamiento de las diversas sociedades balleneras. Los resultados los cotejamos con la información que aparece sobre estas empresas en el Diario Oficial. En la Biblioteca Nacional de Santiago de Chile buscamos en los diarios El Correo de Valdivia y La Cruz del Sur de Ancud, algunos datos sobre las actividades balleneras en la planta. Pero tal vez lo más interesante sea un pequeño conjunto de fotografías sobre la planta de Guafo en manos privadas en Valdivia, las que nos permitieron "imaginarla" visualmente.

Sostuvimos intensas conversaciones o "entrevistas" con personas que participaron en las faenas balleneras de isla Guafo, que pudieron observarlas o que simplemente escucharon de sus mayores algunas historias y relatos sobre ellas. Las conversaciones las sostuvimos en Melinka, Quellón, Castro y Ancud; en Corral, Amargos, San Carlos de Corral y Valdivia, en Quintay y Quilpué. Son "recuerdos", es decir, interpretaciones contemporáneas de hechos (o, para ser justo, de interpretaciones) pretéritos.

No pudimos visitar las ruinas de la planta ballenera de Guafo, pero obtuvimos un conjunto de fotografías que nos permite formarnos una idea de la situación actual de sus edificaciones e instalaciones. Nos interesaba "estar ahî", contemplar y sentir las "ruinas", participar directamente de su abandono. Las fotografías son, sin embargo, un pálido sustituto de estas sensaciones.

\section{Las operaciones balleneras en isla Guafo}

La isla Guafo se encuentra situada entre los paralelos $43^{\circ} 52^{\prime}$ y $43^{\circ} 69^{\prime} \mathrm{S}$ y los meridianos $74^{\circ}$ 55 y $74^{\circ} 84^{\prime}$ W., a unos $38 \mathrm{~km}$ al suroeste de la Isla Grande de Chiloé, en la boca del golfo del Corcovado (Fig. 2). La isla Guafo tiene una superficie de 214 $\mathrm{km}^{2}$ y su perímetro costero llega a $72 \mathrm{~km}$. La isla 


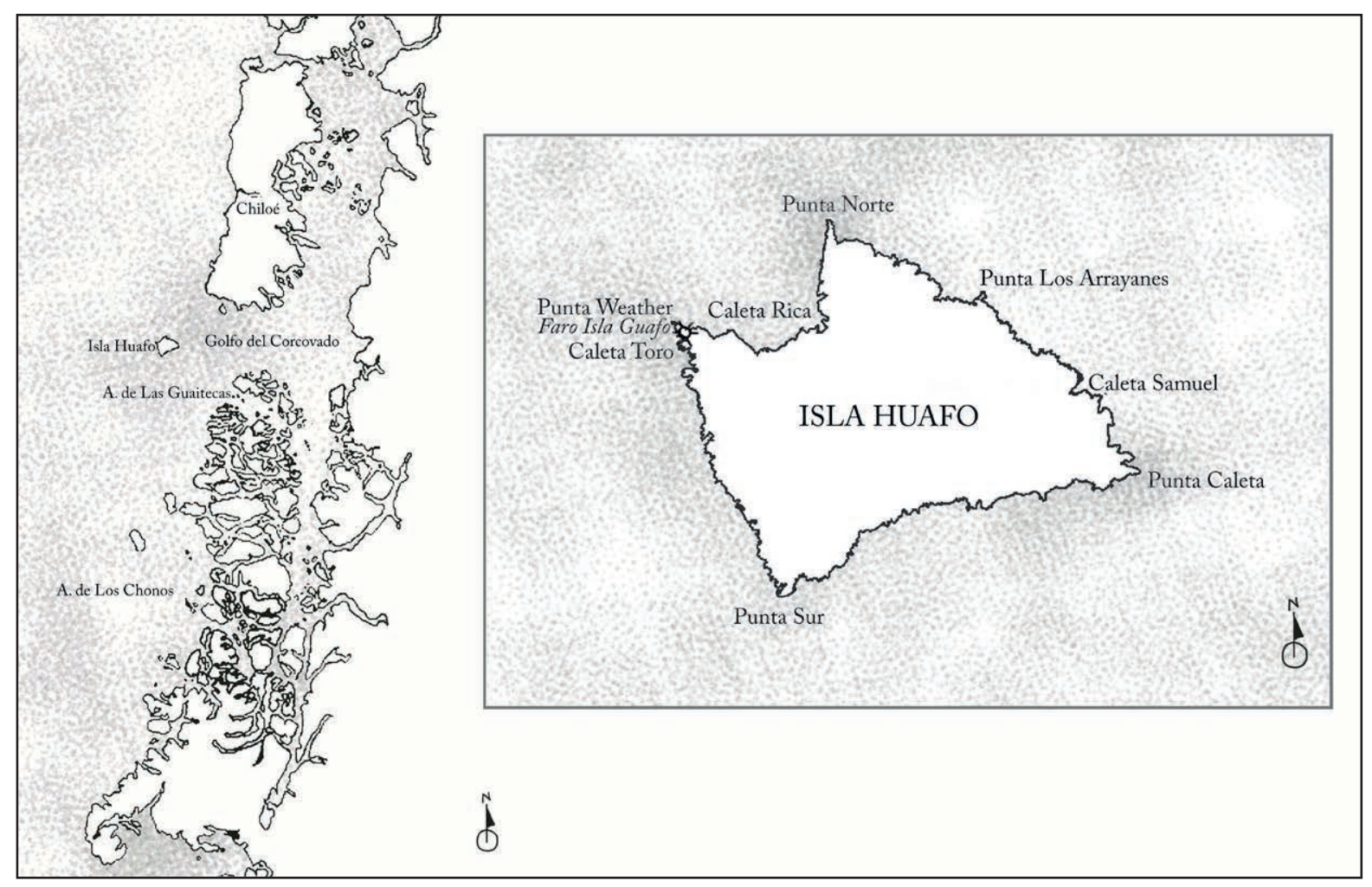

Fig. 2 Ubicación y Mapa de Isla Guafo [Dibujo Paula de la Fuente]

posee una topografía montañosa, con pequeños valles escarpados recorridos por esteros encajonados, siendo su altura máxima $306 \mathrm{~m}$. La costa es, en su mayor parte, bastante acantilada, inaccesible incluso en condiciones atmosféricas normales, pero con algunas laderas y playas de arena (Clark et al., 1984). El clima es templado lluvioso, con temperatura promedio máximas de $12,3^{\circ} \mathrm{C}$ y mínimas de $6,7^{\circ} \mathrm{C}$. Las precipitaciones anuales son de $1.670 \mathrm{~mm}$, siendo mayo el mes más lluvioso, con $212 \mathrm{~mm}$ y enero el más seco, con $88 \mathrm{~mm}$. Predomina el bosque laurifolio de Chiloé, siendo el olivillo la especie más frecuente (Reyes-Arriagada et al., 2009). Se encuentra deshabitada, excepto por la dotación de marinos que atiende el faro de la isla y algunos pescadores que frecuentan temporalmente sus costas (Clark et al., 1984).

Los alrededores de la isla siempre fueron considerados como un caladero importante para los balleneros que recorrieron las costas chilenas durante la primera mitad del siglo XIX. El coto de caza de Guafo se ubica al oeste y sur este de [la isla] Guafo donde, desde comienzos de septiembre hasta diciembre, hay cachalotes en gran abundancia, siendo la boca del golfo de las Guaitecas su lugar favorito de alimentación. La ballena franca o negra frecuenta Guafo en gran número y se cree que en algunas temporadas aparecen en estos lugares hasta marzo (Fanning, 1833: 482). La zona de la boca de Guafo continuó siendo utilizada por los balleneros durante todo el siglo XIX pero no tenemos datos fiables relativos a las capturas o cantidades de aceite producidas durante ese siglo.

La caza moderna de ballenas comienza en Chile en la primera década del siglo XX con la formación de varias sociedades especializadas en la captura y procesamiento de cetáceos (Pastene \& Quiroz, 2010). En los inicios del siglo hubo tres empresas que trabajaron en las costas de Chile usando el modelo noruego de caza. Todas ellas tuvieron operaciones de distinta envergadura en los alrededores de isla Guafo. La Sociedad Ballenera de Magallanes caza ballenas en las temporadas 1910 y 1911 utilizando el vapor RUBENS como buque factoría anclado en Puerto Low, Islas Guaitecas (Quiroz \& de la Fuente, 2012). Los buques de la Sociedad Ballenera y Pescadora 
de Valdivia acostumbraban a operar en la zona: el 6 de diciembre [de 1909] llega el NORUEGA con una ballena azul, que había sido cazada en la isla Guafo (Aagaard, 1930: 368), pero los cetáceos eran procesados y contabilizados en su planta de San Carlos de Corral (Quiroz, 2010a). La empresa que se establece más cerca de la isla Guafo es la Ballenera del Pacífico, que construye en 1909 una planta en la isla San Pedro, al sureste de la Isla Grande de Chiloé (Quiroz, 2010b), capturando en la zona durante su primera temporada [1909-1910] treinta y siete ballenas, entre ellas treinta y dos ballenas azules, cuatro ballenas de aleta y una jorobada, que en total dieron 1,327 barriles de aceite (Aagaard 1930, I: 367; cf. Risting, 1922: 559).

\section{Las sociedades balleneras}

La posibilidad de procesar los cetáceos cerca de sus caladeros será un gran incentivo para distintos empresarios que formaron sociedades para desarrollar operaciones desde la isla. La planta ballenera de Guafo fue construida por la Sociedad Pescadores de Chile y Noruega en la temporada 1922-1923 y operada por esa empresa hasta 1924, cuando su gestión fue traspasada, primero a la Sociedad Thomassen y Cia. y luego a la Sociedad Ballenera de Corral. A fines de 1935 la Compañía Industrial S.A. adquiere los activos y pasivos de la empresa valdiviana, entre ellos la planta de Guafo, operándola hasta la temporada 1937-1938, cuando es cerrada y luego desmantelada.

\section{La Sociedad Pescadores de Chile y Noruega}

El comerciante Francisco Molina, de Valdivia,

2 Escrituras Públicas de Santiago [Pedro N. Cruz], 1921, ${ }^{\circ}$ 807, 25 de abril de 1921, v. 2921, fs.742-744. Archivo de la Administración del Archivo Nacional [Santiago, Chile].

3 Registro de Comercio de Valparaíso, 1921, n 209, 30 de abril de 1921 . fs. $211 v-212$. Archivo de la Administración del Archivo Nacional [Santiago, Chile].

4 Escrituras Públicas de Santiago [Pedro N. Cruz], 1921, n 108, 9 de mayo de 1921, V. 2922, fs. 98-99. Archivo de la Administración del Archivo Nacional [Santiago, Chile].

5 Hay algunas diferencias con los datos que aparecen en los registros internacionales de buques. Para Det Norske Veritas (1913), el Penguin tenía un arqueo de 169 GRT y 62 NRT, con 101 pies de eslora, 20,1 pies de manga y 11,9 pies de puntal, con un motor de 60 NHP, y para el Lloyd's Register (1924) su arqueo era de 173 GRT y 77 NRT y tenía las mis- y José María Raposo, de Santiago, protocolizan el 25 de abril de 1921 las escrituras de una sociedad colectiva por acciones denominada Pescadores Chile y Noruega ante el Notario de Santiago Pedro Nolasco Cruz. El capital social era de doscientos cincuenta mil pesos divididos en diez mil acciones de veinticinco pesos cada una, de las que ocho mil corresponden a Francisco Molina y dos mil a José María Raposo. Su objetivo era esplotar la industria de la pesca en las costas de Chile i del Ecuador i mares adyacentes, i beneficiar el pescado ahumándolo o colocándolo en conserva o llevando el pescado a los puertos de la República para su consumo inmediato, i se dedicará también a la venta o refinación del aceite de ballena i a todas las industrias que se relaciones con la pesca. La sociedad tiene como proyecto fusionarse más adelante con una firma noruega compuesta de navieros y capitanes de buques. El domicilio de la sociedad será "por ahora Valparaíso" y su gerente Godofredo Oettinger, de Valdivia, que tendrá a su cargo, entre otras cosas, ceder parte del haber social a la firma noruega a que antes se ha hecho referencia, que recibirá una remuneración mensual de mil pesos ${ }^{2}$. La sociedad es inscrita en el Registro de Comercio de Valparaíso el 30 de abril de $1921^{3}$. Los estatutos de la sociedad son modificados unos días más tarde, cambiando en su objetivo la frase se dedicará también a la venta o refinación de aceite de ballena por se dedicará también a la pesca de ballenas y a la venta y refinación de aceite de ballena ${ }^{4}$.

Para cumplir con sus objetivos balleneros, la sociedad adquiere en 1921, en ochenta mil nacionales, moneda argentina, el vapor Penguin, de ciento sesenta $i$ nueve, cuarenta $i$ tres toneladas

mas dimensiones, pero con un motor 41 NHP. Los ochenta mil nacionales se desglosan en "veinticinco mil nacionales que la Sociedad Pescadores de Chile i Noruega envió a Lundt Hermanos i Compañía, de Buenos Aires" en septiembre de 1921, "quince mil nacionales que el señor Trygge Haslund, como representante de Lund Hermanos i Compañía, debía pagar a la sociedad por indemnización según transacción otorgada en el juicio indicado anteriormente" y "cuarenta mil nacionales que la sociedad reconoce deber i se obliga a pagar al American Foreign Banking Corporation en diez i ocho meses", abonándole un $10 \%$ anual. Escrituras Públicas de Valdivia [Miguel Varela], 1922, Tomo I, n 197, 22 de febrero de 1922, fs. 124v-129. Archivo Conservador de Bienes Raíces de Valdivia [Valdivia, Chile]. 


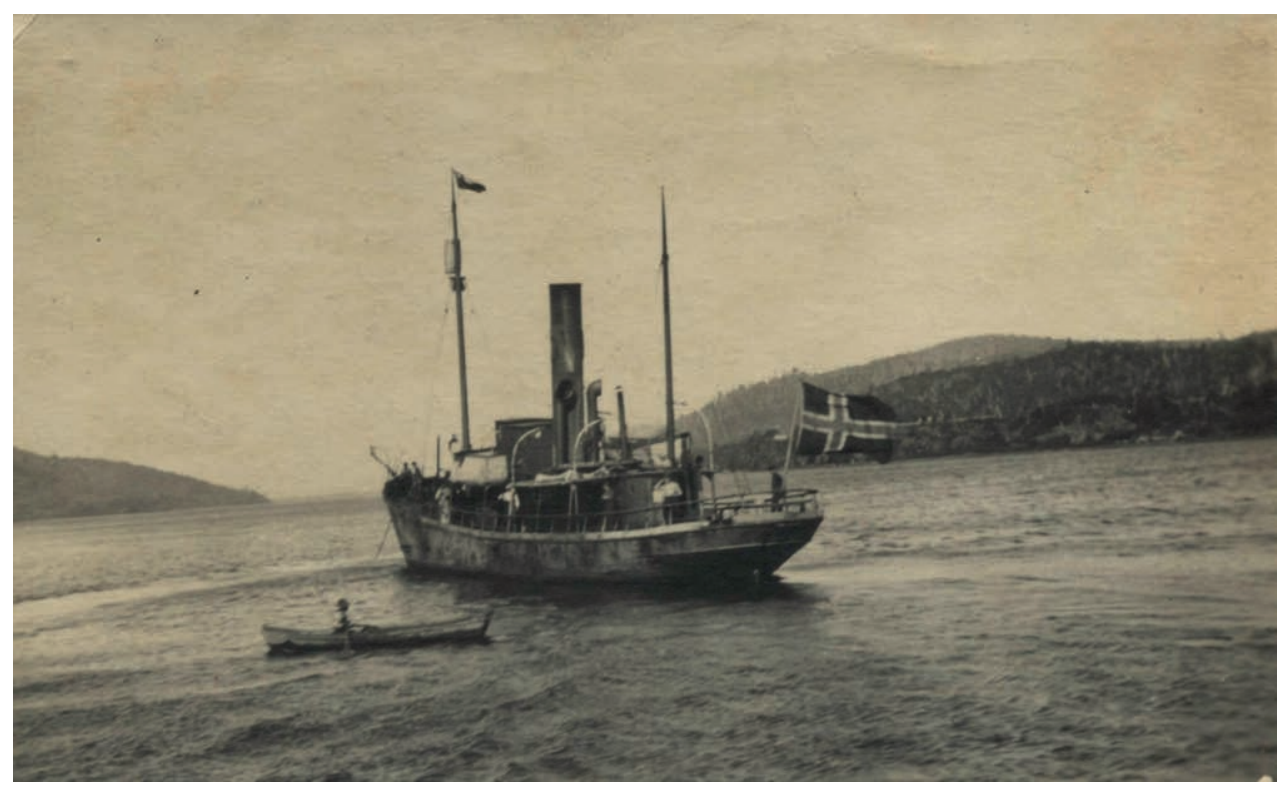

Fig. 3 El vapor Penguin, con las banderas de Chile y Noruega, fondeado en Niebla, 1921 [Foto gentileza de Fernando Oettinger].

de registro bruto $i$ sesenta $i$ dos, veintisiete toneladas de registro neto $i$ que se individualiza del modo siguiente: eslora ciento seis pies diez pulgadas, manga veinte pies i puntal doce pies siete pulgadas ${ }^{5}$. El Penguin era un ballenero a vapor, con casco de acero, construido en 1909 por A/S Framnaes mek. Verksted de Sandefjord, Noruega (\#79) para A/S Ocean de Larvik, Noruega (Fig. 3). El buque tenía un motor de vapor, a carbón, de triple expansión y tres cilindros, de 60 NHP fabricado por Akers mek. Verksted, de Christianía, Noruega (Bogen, 1948). Fue utilizado entre 1909 y 1912 en la caza de ballenas desde la estación terrestre de New Fortuna Bay (posteriormente Ocean Harbour), en las Islas Georgias del Sur (Hart, 2006). En 1913 fue arrendado a la Compañía Argentina de Pesca, que operaba desde Grytviken, Islas Georgias del Sur (Hart, 2001: 522). Fue requisado en 1914 por la Real Marina Noruega y devuelto en 1920 a A/S Vestfold, compañía que surge de la fusión entre A/S Ocean y A/S Sandefjord (Hart 2006). El Penguin es vendido en 1921 a la Sociedad Pescadores de Chile y Noruega a través de los oficios de Wictor Esbensen, gerente de la Compañía Argentina de Pesca (Hart, 2001).

6 Escrituras Públicas de Santiago [José Vicente Fabres], 1921, n 3, 2 de noviembre de 1921, V. 2937, fs. 2v-4v. Archivo de la
Ese mismo año, 1921, Carlos Oettinger arrienda, en tres mil pesos anuales, a Alamiro Guzmán Moreno cincuenta hectáreas de terreno en dicha isla [Guafo] terreno que el arrendatario elegirá en los seis meses siguientes a la fecha de esta escritura con el objeto exclusivo de instalar en la isla, estaciones destinadas a la pesca. La duración del contrato es de siete años a contar de la fecha de esta escritura y el arrendatario queda facultado para traspasar este contrato, si lo cree conveniente, a la Sociedad Pescadores Chile y Noruega. El arrendatario tendrá derechos para aprovechar las maderas i leñas que en la parte arrendada de la isla existan, siempre que sea para los usos de la industria que debe instalar y también podrá explotar i beneficiar las minas de carbón de piedra u otras sustancias minerales que en la isla existan, pagando al arrendador un peso, moneda nacional, por cada tonelada que se extraiga. El contrato se constituye también en una promesa de venta del dueño de la isla denominada 'Huafo', situada en el departamento de Castro, provincia de Chiloé, por toda la isla a su arrendatario, por el precio de tres millones de pesos, moneda nacional ${ }^{6}$. 
Debido al fracaso en las negociaciones para fusionarse con una "firma noruega", en 1922 los estatutos son nuevamente modificados, transformando la sociedad colectiva por acciones en una comunidad y cambiando su domicilio de Valparaíso a Valdivia ${ }^{7}$.

La prensa local informa que hacia finales de 1922 tha iniciado sus trabajos la nueva sociedad ballenera titulada Sociedad de Pescadores 'Chile y Noruega'. Hoy zarpará al sur el 'Pinguin', el más grande de los buques balleneros que hay en la costa chilena, llevando a remolque al buque 'Leonora'8, a cuyo bordo van las casas y demás instalaciones para la fábrica que se instalará en Puerto Low, que es donde estará el asiento industrial de la nueva ballenera. Al bordo del 'Pinguin' van el Gerente de la Sociedad, Sr. Godofredo Oettinger y don José María Raposo, uno de sus propietarios, que dirigirán las instalaciones. La nueva sociedad ballenera está llamada a tener un gran auge industrial ${ }^{9}$. Estos datos son repetidos, con algunas modificaciones $e$ imprecisiones, en otros informes contemporáneos. En uno se indica que el ballenero Penguin y el vapor LEONORA, que sirve como una factoría flotante, dejaron Corral [enero 1923] para el sur y en breve la empresa poseería un nuevo vapor ballenero, pero aún no ha llegado (Allen, 1923: 46). En otro informe se señala que la empresa tiene en servicio de pesca al vapor ballenero Penguin, de último modelo, adquirido en Noruega y que la base de operaciones y la administración

7 Escrituras Públicas de Santiago [Pedro N. Cruz], 1922, $\mathrm{n}^{\circ}$ 446, 3 de octubre de 1922, V. 2974, fs. 475v-476v, Archivo de la Administración del Archivo Nacional [Santiago, Chile].

8 El buque LEONORA era, al parecer, una goleta que, al mando del capitán Evaristo Calderón, naufraga el 29 de junio de 1923 en Caleta Samuel, isla Guafo, durante un fuerte temporal. Escrituras Públicas de Valdivia [Miguel Varela], 1923, Tomo III, $n^{\circ}$ 1370, 14 de febrero de 1923, fs. 1040v-1041v. Archivo Conservador de Bienes Raíces de Valdivia [Valdivia, Chile].

9 El Correo de Valdivia (Valdivia), 14 de enero de 1923.

10 Las principales fuentes de información sobre las capturas de ballenas y producción de aceite, guano y otros derivados, son las estadísticas internacionales oficiales reunidas por la Norsk Hvalfangsteforeging [Asociación Noruega de Balleneros] con sede en Sandefjord, Noruega, y publicadas desde 1912 en la revista Norsk Hvalfangst-Tidende [La Gaceta Ballenera Noruega]. En 1930 el gobierno noruego se encuentra en Puerto Low, islas Guaitecas, al sur de Chiloé, donde se elabora todos los tipos de aceite y abono de hueso y carne de ballena, siendo su capacidad productora, por ahora, sólo de 5.000 barriles de aceite por año agregando que próximamente instalará una fábrica flotante, que se fondeará en la península de Tres Montes, donde cuenta con concesión fiscal por 25 años (Swett, 1923: 1170).

En definitiva la planta ballenera se construirá en Caleta Samuel, Isla Guafo, y no en Puerto Low, Islas Guaitecas, aunque algunas instalaciones se construyeron en ese lugar. Los nuevos proyectos y las adquisiciones indicadas nunca se concretarán. De acuerdo a las estadísticas internacionales oficiales $^{10}$ la expedición de 1922-1923 habría logrado cazar solamente cuatro ballenas, dos azules y dos de aleta, las que produjeron 140 barriles de aceite, debido a que la compañía no pudo empezar a cazar hasta muy avanzada la temporada y que además el establecimiento no se ha construido completamente, ya que se han limitado a instalar una caldera abierta y un cocinador pequeño (Anónimo, 1923: 101) ${ }^{11}$.

\section{La Sociedad de Pesca \\ Thomassen y Compañía}

El año 1924 es un año crítico y de gran movimiento societario respecto de la gestión de la planta ballenera de Guafo. El 31 de diciembre de 1923 se hace un balance de los activos y pasivos

establece el Bureau of International Whaling Statistics para llevar un registro acucioso de las capturas de cetáceos, las que publicará anualmente en la revista International Whaling Statistics. En 1984 esta responsabilidad será asumida por la Comisión Ballenera Internacional [InternationalWhaling Commission] con asiento en Cambridge, Inglaterra.

11 La traducción del texto original en noruego es de responsabilidad del autor.

12 Escrituras Públicas de Valdivia [Miguel Varela], 1924, Tomo I, n 220, 13 de febrero de 1924, fs. 167-168. Archivo Conservador de Bienes Raíces de Valdivia [Valdivia, Chile].

13 Godofredo Oettinger Stegmaier nace en Valdivia, Chile, el 27 de enero de 1890. Casado con Hertha Eisendecher, tuvo dos hijos, Godofredo y Helen. Estudió en la Deutsche Schule de Valdivia y en el English Institute de Santiago. Luego estudió comercio en Manchester, Inglaterra. Se dedicó principalmente al negocio naviero (datos obtenidos de http://historiadevaldivia-chile.blogspot.com/2014/01/ familia-oettinger.html). 


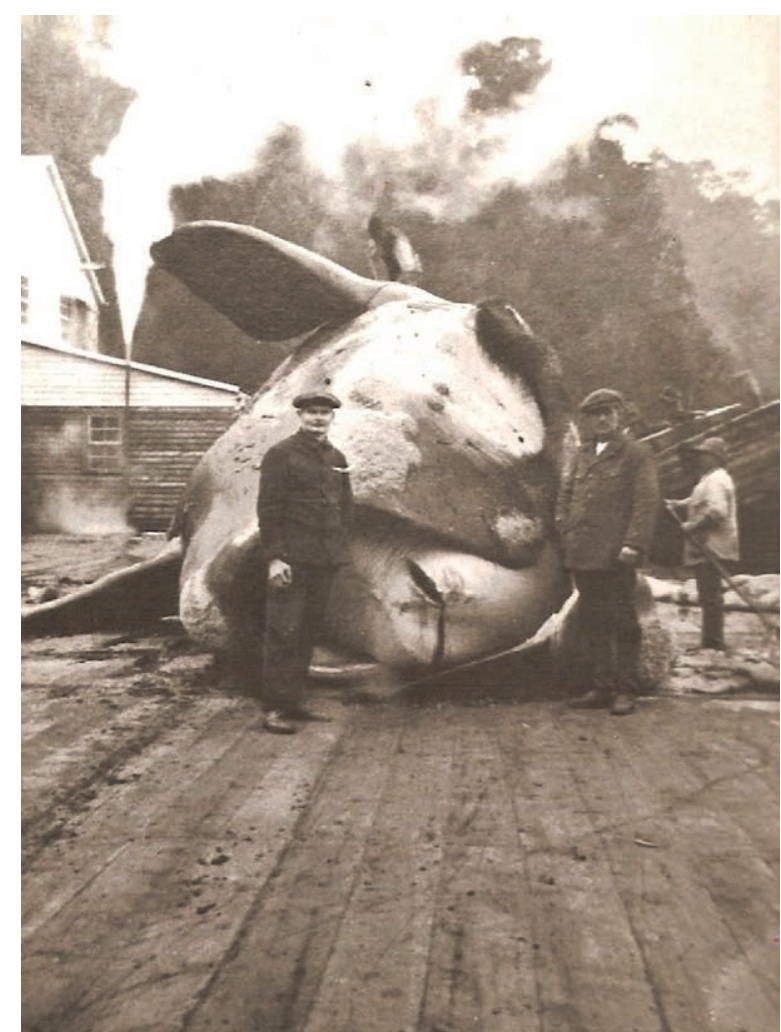

Fig. 4 T. M Thomassen en la planta de Guafo, 1924 [Foto gentileza de Irene Aguilar Thomassen].

de la Sociedad Pescadores de Chile y Noruega, obteniendo como resultado activos por $\$ 623.552,26$ y pasivos por $\$ 252.252,45$, con un saldo positivo de $\$ 371.289,81$. Los socios deciden transferir sus bienes ${ }^{12}$ a los señores Godofredo Oettinger ${ }^{13}$

14 Tiedemann M Thomassen nació en Bergen, Noruega, el 8 de agosto de 1877. Casado con Annja Nygaard, llega a Chile en 1914 a bordo del vapor ORITA. Fue administrador de la planta ballenera de San Carlos de Corral entre 1917 y 1920. Trajo más tarde desde Noruega a sus hermanos Víctor y Thomas, los que también formaron familia y se quedaron en Chile. Tuvo 5 hijos, Marta, Tomás, Norman y Aase, nacidos en Noruega, y Ana María, nacida en Valdivia, Chile. Fallece en Santiago, el 8 de noviembre de 1925, poco tiempo después de vender su empresa a la Sociedad Ballenera de Corral (datos proporcionados por su nieta Irene Aguilar Thomassen, Valdivia, Chile).

15 Escrituras Públicas de Valdivia [Miguel Varela], 1924, Tomo I, n 222, 13 de febrero de 1924, fs. 169-176. Archivo Conservador de Bienes Raíces de Valdivia [Valdivia, Chile].

16 Escrituras Públicas de Valdivia [Miguel Varela], 1924, Tomo I, $\mathrm{n}^{\circ} 221,13$ de febrero de 1924, fs. 168-169. Archivo Conservador de Bienes Raíces de Valdivia [Valdivia, Chile].

17 Escrituras Públicas de Valdivia [Miguel Varela], 1924, Tomo y Tiedemann Thomassen ${ }^{14}$ (Fig. 4), quiénes forman una sociedad en comandita por acciones denominada Sociedad de Pesca Oettinger, Thomassen y Compañía ${ }^{15}$, y disolver la Sociedad Pescadores de Chile y Noruega ${ }^{16}$. El capital social de la nueva sociedad, sería de $\$ 500.000$ repartido en quinientas acciones de $\$ 1.000$ cada una, y estaba constituido por los aportes que hacen los socios gestores consistentes en el establecimiento ballenero i refinería de aceite, situado en la isla de Huafo, en el vapor ballenero Penguin, útiles de pesca, existencia en aceite, carbón $i$ leña, créditos $i$ en dinero en efectivo que en este acto transfieren a la sociedad ${ }^{17}$. Los socios gestores eran G. Oettinger y T, Thomassen, y los socios comanditarios O. Eisendacher, E. Stack, A. Stegmaier, H. Eisendacher de Oettinger, y A. Nygaard de Thomassen ${ }^{18}$. Se dejaba establecido que la explotación del negocio ballenero, a contar desde el treinta y uno de diciembre último corre por cuenta i riesgo de los compradores ${ }^{19}$. Godofredo Oettinger desiste de ser socio gestor de la empresa por lo que este intento no prospera y se dejan sin efecto todas las escrituras que lo sustentaban.

El 12 de febrero de 1924 se realiza un nuevo balance de la sociedad, que arroja como resultado la existencia de activos por $\$ 752.252,45$ y pasivos por $\$ 354.370,06$, con un saldo positivo de $\$ 397.882,39$. Los socios deciden transferir los activos y pasivos ${ }^{20}$ de la Sociedad de Pescadores de Chile y Noruega a una nueva sociedad, también en

I, $\mathrm{n}^{\circ}$ 222, 13 de febrero de 1924, fs. 169-176. Archivo Conservador de Bienes Raíces de Valdivia [Valdivia, Chile].

18 G. Oettinger, 372 acciones, T, Thomassen 25 acciones, O. Eisendacher, 25 acciones, E. Stack, 24 acciones, H. Eisendacher de Oettinger, 46 acciones, A. Stegmaier, 4 acciones, y A. Nygaard de Thomassen, 4 acciones. Escrituras Públicas de Valdivia [Miguel Varela], 1924, Tomo I, $\mathrm{n}^{\circ}$ 230, 14 de febrero de 1924, fs. 181-182v. Archivo Conservador de Bienes Raíces de Valdivia [Valdivia, Chile].

19 Escrituras Públicas de Valdivia [Miguel Varela], 1924, Tomo I, n²20, 13 de febrero de 1924, fs. 167-168. Archivo Conservador de Bienes Raíces de Valdivia [Valdivia, Chile].

20 Escrituras Públicas de Valdivia [Miguel Varela], 1924, Tomo I, n² 244, 16 de febrero de 1924, fs. 192v-194. Archivo Conservador de Bienes Raíces de Valdivia [Valdivia, Chile]. 21 Escrituras Públicas de Valdivia [Miguel Varela], 1924, Tomo I, $\mathrm{n}^{\circ}$ 244, 16 de febrero de 1924, fs. 192v194. Archivo Conservador de Bienes Raíces de Valdivia [Valdivia, Chile]. 
comandita por acciones, denominada Sociedad de Pesca Thomassen y Compañía, cuyo socio gestor era Tiedeman Thomassen, ahora en solitario ${ }^{21}$. La sociedad se constituye en Valdivia, con el objetivo de a) adquirir el establecimiento ballenero, el vapor Penguin i demás bienes de la Sociedad Pescadores Chile i Noruega; b) continuar la explotación de la industria de la pesca, beneficio de ballenas y refinería de aceite, c) dedicarse a cualquier otra rama de la industria pesquera que se estimare oportuno atender. El capital social era el mismo, de $\$ 500.000$, constituido por el establecimiento ballenero de Guafo, vapor ballenero Penguin, útiles de pesca, existencia en aceite, carbón y leña, créditos y dinero efectivo aportado por los socios $i$ dividido en quinientas acciones de un mil pesos cada una, de las cuales corresponden al socio gestor veinticinco acciones y las demás a los socios comanditarios. La administración y en especial la dirección técnica de los negocios estará a cargo del socio gestor y Godofredo Oettinger permanecerá como gerente y tendrá la administración general i el uso de la razón social, anteponiendo a su firma personal, el nombre de la sociedad ${ }^{22}$. Los socios comanditarios eran ahora Francisco Molina, José María Raposo, los antiguos dueños de la Sociedad Pescadores Chile y Noruega, y algunos de sus acreedores como Otto Eisendecher, Alberto Stegmaier y Anna Nygaard de Thomassen ${ }^{23}$.

El 30 de abril de 1924, en Junta General de Accionistas, con la asistencia de todos ellos el Presidente de la Sociedad de Pesca Thomassen y Compañía José María Raposo informa que se habian iniciado gestiones para fusionar la sociedad con la Sociedad Ballenera de Corral $i$ que el resultado de esas gestiones era la siguiente proposición: [...] La Sociedad de Pesca Thomassen y Compañía transfiere a la Sociedad Ballenera de Corral el activo de la sociedad incluyendo la existencia actual de aceite por el

22 Escrituras Públicas de Valdivia [Miguel Varela], 1924, $\mathrm{n}^{\circ}$ 245, 16 de febrero de 1924, fs. 194-201. Archivo Conservador de Bienes Raíces de Valdivia [Valdivia, Chile].

23 Francisco Molina tenía 298 acciones, José María Raposo, 74, Otto Eisendecher, 70, Alberto Stegmaier, 28, Anna Nygaard de Thomassen, 4, T. Thomassen, 25, lo que completa el total de 500 acciones. Escrituras Públicas de precio de cuatrocientos sesenta mil ciento diez peso (\$460.110) en acciones de la Sociedad Ballenera de Corral i setenta i ocho mil noventa pesos en dinero en efectivo (\$78.090) [...]. El Presidente manifestó que esta proposición era el resultado de laboriosas gestiones i agregó que, en su concepto, había manifiesta conveniencia, ya que no había sido posible mejorarla en atención a la circunstancia de que la Sociedad Ballenera de Corral tenía los capitales listos para establecerse en las cercanías de Guafo, lo que, como era natural, tenía que traer una formidable competencia entre las dos sociedades, i como la Sociedad Thomassen i Compañía tenía un capital reducido, la competencia les sería claramente desfavorable, que, además el negocio de pesca de ballena en una sola mano con elementos de trabajo i dinero, ofrece seguridades de que tomaría gran impulso i compensaría con sus utilidades a los accionistas de ambas sociedades. La Junta acepta por unanimidad la propuesta, acordando protocolizar una promesa de compraventa con Jorge Anwandter, Gerente de la Sociedad Ballenera de Corral, donde se vende, en la suma indicada anteriormente, los activos de la Sociedad de Pesca Thomassen y Compañía, consistentes en el vapor ballenero Penguin, establecimiento de beneficio de ballenas $i$ refinería de aceite de Huafo, existencias en carbón, materiales de pesca, maquinarias $i$ enseres i útiles, que se encuentran en Huafo i en Puerto Low, exceptuando la existencia en aceite y barbas de ballena y sus pasivos ${ }^{24}$.

En un informe elaborado por el Guarda Pesca de Corral en el mes de mayo de 1924 a solicitud de la Inspección General de Bosques, Pesca y Caza, se indica que la Compañía Ballenera de Huafo, que empezó sus labores en noviembre del año pasado, ha cazado hasta abril último 45 ejemplares de ballenas, de las cuáles cinco son righwales. Esta compañía ha tenido una utilidad de las ballenas de 1.570 barriles de 200 litros

Valdivia [Miguel Varela], 1924, $\mathrm{n}^{\circ}$ 246, 18 de febrero de 1924, fs. 201-202v. Archivo Conservador de Bienes Raíces de Valdivia [Valdivia, Chile].

24 Escrituras Públicas de Valdivia [Miguel Varela], 1924, Tomo II, $\mathrm{n}^{\circ} 653,1^{\circ}$ de mayo de 1924, fs.534--537. Archivo Conservador de Bienes Raíces de Valdivia [Valdivia].

25 El Correo de Valdivia (Valdivia), 24 de mayo de 1924: 9. 
de aceite de primera calidad y 1.230 [ton] de barbas $^{25}$. Estos datos corresponden a la campaña 1923-1924, aún sin finalizar.

\section{La Sociedad Ballenera de Corral}

La Sociedad Ballenera de Corral era una sociedad anónima constituida el 22 de diciembre de 1913, para la pesca i beneficio de ballenas $i$ elaboración de sus derivados, con un capital social de veinte mil libras esterlinas, divididas en dos mil acciones de diez libras esterlinas cada una, totalmente pagadas ${ }^{26}$. Después de los trámites exigidos por las autoridades, se autoriza la existencia de la sociedad, aprobando sus estatutos y declarándola legalmente instalada, el 24 de julio de 1914 mediante Decreto Supremo $\mathrm{N}^{\circ} 2.012$ del Ministerio de Hacienda ${ }^{27}$. Debido a una reorganización de la empresa, las inscripciones de 1914 fueron dejadas sin efecto en $1916^{28}$ y la sociedad se constituye nuevamente durante el año siguiente, aprobando sus estatutos y quedando legalmente instalada mediante Decreto Supremo $\mathrm{N}^{\circ} 1.638$ del Ministerio de Hacienda, el 31 de julio de $1917^{29}$.

El 14 de mayo de 1924, en Junta General Extraordinaria de Accionistas, el presidente de la Sociedad Ballenera de Corral solicita una modificación de sus estatutos que consiste en aumentar el capital social de \$1.561.800 a \$2.100.000, [...] para poder adquirir el establecimiento ballenero de la Sociedad de Pesca Thomassen y Compañía, conforme al plan ideado por el Directorio ${ }^{30}$. La Junta acepta

26 Escrituras Públicas de Valdivia [Jerardo Ríos], 1913, Tomo VI, $\mathrm{n}^{\circ}$ 470, 22 de diciembre de 1913, fs. 351-355v. Archivo Conservador de Bienes Raíces de Valdivia [Valdivia].

27 Registro de Sociedades de Valdivia, 1914, $\mathrm{n}^{\circ} 31$ y $\mathrm{n}^{\circ}$ 32, 13 de agosto de 1914, fs. 25v-30v; 30v-31. Archivo Conservador de Bienes Raíces de Valdivia [Valdivia]. Diario Oficial (Santiago de Chile), 20 de agosto de 1914.

28 Escrituras Públicas de Valdivia [Miguel Varela], 1916, Tomo II, $\mathrm{n}^{\circ} 1208,5$ de diciembre de 1916, fs. 752-753. Archivo Conservador de Bienes Raíces de Valdivia [Valdivia].

29 Registro de Sociedades de Valdivia, 1917, $n^{\circ} 26,18$ de agosto de 1917, fs. 25v-29. Archivo Conservador de Bienes Raíces de Valdivia [Valdivia]; Diario Oficial (Santiago de Chile), 14 de agosto de 1917.

30 Escrituras Públicas de Valdivia [Miguel Varela], 1924, Tomo la propuesta y la solicitud de modificación de estatutos de la Sociedad Ballenera de Corral es aprobada, mediante el D. S. N ${ }^{\circ} 1264$ del Ministerio de Hacienda, el 23 de junio de 1924, autorizando la emisión de nuevas acciones hasta alcanzar el capital indicado ${ }^{31}$. La Sociedad Ballenera de Corral compra los activos de la Sociedad de Pesca Thomassen y Compañía y se hace cargo de la planta ballenera ubicada en Caleta Samuel, isla Guafo $^{32}$

Para hacer efectiva las operaciones de la planta ballenera, Carlos Oettinger actualiza el contrato de arriendo que había establecido en 1921 con Alamiro Guzmán Moreno, dueño del terreno en Isla Guafo, prorrogándolo por siete años adicionales a contar del vencimiento del primer contrato y aumentando el canon anual a seis mil pesos ${ }^{33}$, lo que implica su término recién en 1935. El contrato de arriendo es luego perfeccionado con una escritura complementaria para fijar las cincuenta hectáreas de suelo dadas en arrendamiento. Los deslindes que la separan del resto de la isla son: de la desembocadura del estero que cae en la caleta Samuel sale una línea recta hacia el suroeste de doce kilómetros de largo, de ahí forma el deslinde otra línea recta de un kilómetro de largo rumbo al noroeste y desde este punto otra línea recta al mar con rumbo al norte, abarcando estos límites una cabida aproximada de cincuenta hectáreas, autorizando a extraer leña para el uso de las fábricas y vapores balleneros fuera de la porción de terreno deslindada [...] sin retribución especial e instalar una casa habitación en la parte sureste de la

II, $\mathrm{n}^{\circ} 742,14$ de mayo de 1924, fs. 599-600v. Archivo Conservador de Bienes Raíces de Valdivia [Valdivia].

31 Registro de Sociedades de Valdivia, 1924, n 54, 27 de junio de 1924, fs. 57-60v. Archivo Conservador de Bienes Raíces de Valdivia [Valdivia, Chile].

32 Escrituras Públicas de Valdivia [Miguel Varela], 1924, Tomo II, n 1662, 9 de octubre de 1924, fs. 1297-1299v. Archivo Conservador de Bienes Raíces de Valdivia [Valdivia].

33 Escrituras Públicas de Santiago [José Vicente Fabres], 1925, n 307, 27 de enero de 1925. V. 3232, fs. 282282v. Archivo de la Administración del Archivo Nacional [Santiago, Chile].

34 Escrituras Públicas de Santiago [José Vicente Fabres], 1925, $\mathrm{n}^{\circ}$ 399, 18 de abril de 1925, V. 3233, fs. 338v339. Archivo de la Administración del Archivo Nacional [Santiago, Chile]. 
caleta Samuel, frente al establecimiento, a fin de poder mejor vigilar [lo] ${ }^{34}$.

C. Oettinger establece luego un acuerdo con la Sociedad Ballenera de Corral para el uso del predio de Guafo, formando con la sociedad una comunidad o sociedad de hecho, donde se indica que la Sociedad Ballenera de Corral establecerá en dicha isla por su propia cuenta un establecimiento ballenero $i$ de refinación de aceites y Carlos Oettinger recibirá una utilidad fija de seis mil pesos al año, utilidad que será entregada al señor Carlos Oettinger en una letra bancaria a la vista i a la oren del señor Alamiro Guzmán Moreno, es decir, las utilidades son, en realidad, para el pago del canon anual de arriendo del terreno en isla Guafo. La verdadera "ganancia" de Oettinger se establece en el art. $n^{\circ} 4$ del mencionado contrato, donde la Sociedad Ballenera de Corral se obliga a hacer transportar en las embarcaciones de propiedad del señor Carlos Oettinger o en las que él indique, los aceites, envases, mercaderías i demás carga que la sociedad ballenera tenga que conducir de Corral a Valdivia o viceversa o puntos intermedios por el tiempo que dure el presente contrato. El precio de este servicio se ajustará a la tarifa que rija entre las diversas empresas o agencias de vapores establecidas en esta ciudad $^{35}$.

La Sociedad Ballenera de Corral comienza a procesar ballenas en la planta de Isla Guafo desde la temporada 1924-1925. En un informe elaborado por el Departamento de Comercio Exterior del Reino Unido, en 1927, se indica que La Sociedad Ballenera de Corral ha tenido una temporada exitosa [...] La nueva base en la isla Huafo, establecida en 1925, ha sido muy efectiva y facilita las operaciones en la isla de Chiloé. La producción de aceite y guano ha encontrado una venta rápida, embarques regulares se envian a Europa y la demanda por el fertilizante es mayor que lo suministrado (Scott, 1927: 36). Desafortunadamente no tenemos estadísticas que desagreguen los aportes de las plantas balleneras de San Carlos de Corral y Guafo a la producción de

35 Escrituras Públicas de Valdivia [Miguel Varela], 1925, $\mathrm{n}^{\circ}$ 361, 14 de marzo de 1925, fs.257v-258v. Archivo Conservador de Bienes Raíces de Valdivia [Valdivia, Chile].

36 Acta de la Junta General Extraordinaria de accionistas la Sociedad Ballenera de Corral entre 1924-1925 y 1929-1930.

Recién iniciada la temporada 1930-1931 en Guafo se notó muy pronto una notable escasez de ballenas, que se tradujo en una considerable merma en la producción de aceite, circunstancia que obligó al Consejo Directivo a paralizar ya a fines de febrero las faenas en ese lugar y poner en actividad el establecimiento en Corral, en donde se trabajó hasta principios de mayo. Además, el exceso de producción sobre el consumo fue la causa directa de la enorme baja que sufrieron los precios en Europa [... lo que] hizo imposible toda exportación y la sociedad tuvo que conformarse con surtir el mercado interno del país [...] Estas circunstancias determinaron una disminución en las ventas de los productos de la compañía, disminución que llegó a un $43 \%$ en relación con las efectuadas el año anterior. La compañía reduce el monto de sueldos y jornales y realiza solo los trabajos más indispensables como las reparaciones necesarias para la conservación de los vapores. La empresa declara pérdidas por \$ 367.655,81 en el ejercicio 1930-1931 (Sociedad Ballenera de Corral, 1931, pp. 1-2). En la Junta General Ordinaria realizada en diciembre de 1931 se plantea que la situación de la sociedad parecía tornarse crítica en atención a los bajos precios de los productos en el país y especialmente en Europa y que podría ser necesaria su liquidación ${ }^{36}$. La situación mejora en la temporada siguiente y se hace mucho más holgada: por el momento no existía razón alguna que justificara su liquidación, pues, los productos habian subido de valor en forma apreciable y había mercado en el país para toda la producción, teniendo a la fecha pagadas todas las obligaciones y quedando aun con fondos disponibles para iniciar la nueva temporada de caza que empezará en octubre ${ }^{37}$.

Durante todo el quinquenio 1931-1935 tenemos información segregada de las capturas y productividad de cada una de las planta balleneras de la sociedad (Tabla 1). El total de ballenas capturadas en las dos plantas es relativamente

celebrada el $1^{\circ}$ de agosto de 1932. En Diario Oficial (Santiago de Chile), N 16,515, 2 de marzo de 1933.

37 Acta de la Junta General Extraordinaria de accionistas celebrada el $1^{\circ}$ de agosto de 1932 . En Diario Oficial (Santiago de Chile), $\mathrm{N}^{\circ}$ 16,515, 2 de marzo de 1933. 
Tabla 1. Capturas en la planta de Huafo comparadas con las de la planta de San Carlos, 1931-1935.

\begin{tabular}{c|c|c|c|c|c|c|c|c}
\hline Temporada & Azul & Aleta & Jorobada & Sei & Franca & Cachalote & $\begin{array}{c}\text { Total } \\
\text { Guafo }\end{array}$ & $\begin{array}{c}\text { Total } \\
\text { San Carlos }\end{array}$ \\
\hline 1931 & 3 & 1 & 1 & & & 6 & $\mathbf{1 1}$ & 123 \\
\hline 1932 & 27 & 3 & 3 & 9 & 21 & 24 & $\mathbf{8 7}$ & 84 \\
\hline 1933 & 11 & 17 & 9 & 14 & 11 & 19 & $\mathbf{8 1}$ & 104 \\
\hline 1934 & 15 & 86 & 6 & 3 & 6 & 47 & $\mathbf{1 6 3}$ & $\mathbf{1 6}$ \\
\hline 1935 & 16 & 25 & 14 & 1 & 27 & 37 & $\mathbf{1 2 0}$ \\
\hline Total & $\mathbf{7 2}$ & $\mathbf{1 3 2}$ & $\mathbf{3 3}$ & $\mathbf{2 7}$ & $\mathbf{6 5}$ & $\mathbf{1 3 3}$ & $\mathbf{4 6 2}$ & $\mathbf{4 9 5}$ \\
\hline
\end{tabular}

semejante aunque en algunos años específicos una pese más que la otra.

En 1935 la Sociedad Ballenera de Corral decide vender su negocio ballenero firmando una promesa de venta o contrato ad-referendum a la Compañía Industrial S.A. Esta promesa de venta contempla que la Compañía Industrial adquiere los activos de la Sociedad Ballenera de Corral, y se hace cargo de los pasivos conforme a un balance e inventario que ésta practicaría extraordinariamente el 31 de marzo de 1935. Incluye en esta venta los edificios, construcciones, maquinarias e instalaciones existentes en la Caleta Samuel en la Isla de Guafo, en los terrenos arrendados al señor Alamiro Guzmán Moreno y una serie de embarcaciones menores existentes en la planta de Guafo $^{38}$. La promesa o contrato ad-referendum es aprobada y ratificada unánimemente por sendas reuniones generales extraordinarias de accionistas realizadas el 24 de diciembre de 1935, la de la Sociedad Ballenera de Corral en Valdivia ${ }^{39}$ y la de la Compañía Industrial en Valparaíso ${ }^{40}$. Esta ratificación implicaba para la Sociedad Ballenera de Corral solicitar su disolución y liquidación anticipada y para la Compañía Industrial el

38 Estas embarcaciones eran "una lancha Ñata; una lancha con estanque para agua, inutilizada; una lancha con estanque para agua, nueva; una lancha cuadrada, chica; un bote de quilla, grande; una lancha cuadrada, grande; una chalupa grande de quilla, un bote de quilla, chico y un bote plano, regular tamaño". Escrituras Públicas de Valdivia [Miguel Varela], 1935, n 1829, 4 de diciembre de 1935, f.1742. Archivo Conservador de Bienes Raíces de Valdivia [Valdivia, Chile].

39 Acta de la Reunión General Extraordinaria de accionistas de la Sociedad Ballenera de Corral del 24 de diciembre de 1935. Fondo Ministerio de Hacienda, Decretos, Vol. 14, 1936. Archivo Nacional [Santiago, Chile]. aumento de capital y por ende la reforma de sus estatutos, solicitudes que son aprobadas por los respectivos Decretos Supremos del Ministerio de Hacienda $\mathrm{N}^{\circ} 1380$ y 1381 , ambos del 2 de abril de $1936^{41}$.

En 1935 Carlos Oettinger había prorrogado por dos años el arriendo del terreno en isla Guafo a la sucesión de Alamiro Guzmán Moreno ${ }^{42}$ y, por el mismo tiempo, la sociedad de hecho o comunidad con la Sociedad Ballenera de Corral para la explotación del terreno y caleta, materia de dicho arrendamiento. C. Oettinger acepta también que la Sociedad Ballenera de Corral pueda ceder y transferir sus derechos y obligaciones a la Compañía Industrial, en cualquier momento, durante la vigencia de este pacto ${ }^{43}$. La Sociedad Ballenera de Corral, finalmente, subarrienda en 1936 el terreno a la Compañía Industrial S.A. ${ }^{44}$.

\section{La Compañía Industrial S.A.}

La Compañía Industrial S.A. se forma como sociedad anónima en Valparaíso a fines del año 1900. Varios hombres de negocios vinculados a la industria, tanto de Valparaíso como de Santiago,

40 Acta de la Asamblea General Extraordinaria de accionistas de la Compañía Industrial del 24 de diciembre de 1935. Fondo Ministerio de Hacienda, Decretos, Vol. 14, 1936. Archivo Nacional [Santiago, Chile].

41 Diario Oficial (Santiago de Chile), 13 de abril de 1936.

42 Escrituras Públicas de Santiago [Luis Azócsr Álvarez], 1935, 25 de noviembre de 1935. Notarios de Santiago.

43 Escrituras Públicas de Valdivia [Miguel Varela], 1935, $\mathrm{n}^{\circ}$ 1823, 3 de diciembre de 1935, fs.1735-1736v. Archivo Conservador de Bienes Raíces de Valdivia [Valdivia, Chile].

44 Escrituras Públicas de Valdivia [Miguel Varela], 1936, $\mathrm{n}^{\circ}$ 785, 22 de mayo de 1936, fs.648-651. Archivo Conservador de Bienes Raíces de Valdivia [Valdivia, Chile]. 
se unen para formar la empresa, registrando sus escrituras el 12 de diciembre de 1900 ante el Notario de Valparaíso Tomás Ríos González. El Gobierno rápidamente autoriza su existencia, aprueba sus estatutos y más tarde la declara legalmente instalada (Indus, 1951, pp. 2-3).

La INDUS, con un capital inicial de $£ 75.000$, tenía como objetivo ampliar los establecimientos para la elaboración de productos químicos, abonos artificiales, jabones, velas $e$ industrias anexas de los señores Anwandter \& Körner, en Santiago. Posteriormente ingresa al negocio de los perfumes y detergentes; $y$, a comienzos de los 30, la empresa se involucra en la producción de aceites vegetales $y$ animales tanto para alimento como para uso industrial y también en la producción de margarina vegetal (Indus, 1951: 2). Una serie de dificultades con las importaciones de materias primas, impulsa a la empresa a considerar que las ballenas podían ser una importante fuente de aceite y grasa y, en consecuencia, comienza sus operaciones balleneras en 1936 (Indus, 1951: 2). Para hacerlo adquiere los buques de la Comunidad Chileno Noruega de Pesca (un buque factoría, PRESIDENTE ALESSANDRI, y dos buques cazadores, el CHILE y el NORUEGA), y todos los activos de la Sociedad Ballenera de Corral (Indus 1951: 7), entre los que se contaban las plantas de San Carlos de Corral, la de Caleta Samuel de isla Guafo y los dos buques cazadores restantes, el SAMSON y el SCOTT (Pastene \& Quiroz, 2010).

Sin embargo, el interés en ese momento de la empresa era comenzar la caza pelágica de ballenas, por lo que las plantas costeras de San Carlos de Corral y Guafo sólo fueron utilizadas mientras se adaptaba un nuevo buque factoría, ya que el PRESIDENTE ALESSANDRI fue considerado inadecuado para estos propósitos. En 1939 comienza a operar el buque factoría INDUS BF con sus cuatro cazadores INDUS 1 ex CHILE, INDUS 2 ex NORUEGA, INDUS 3 ex SAMSON e INDUS 4 ex SCOTT en el caladero de Guafo y más al sur, de hecho el INDUS 1 naufraga en las cercanías de la isla Guamblín, al sur de isla Guafo (Quiroz \& de la Fuente, 2012).

El inicio de la caza pelágica implica el abandono y posterior desmantelamiento de las plantas costeras de San Carlos de Corral y Guafo.

\section{Contactos con los recuerdos}

La planta ballenera de Guafo está presente hoy en los recuerdos de personas que la conocieron o escucharon hablar de ella. Raúl Pavié nos contaba en su casa de Amargos, cerca de Corral, Valdivia, que en los primeros momentos de operación de la planta en Caleta Samuel en Guafo estuvo un abuelo mío a cargo, se llamaba Giolindo Pavié, él estuvo a cargo de la planta que había en Guafo, allá tenían unos fogones no más, y unas ollas de fierro, de más o menos una tonelada cada una, y ahí tenían una pequeña rampla y vamos tirando, y después acarreaban todo el líquido, todo [...] en la planta de Guafo, trabajaban pocos, yo creo que eran turnos de más o menos 24 o 30 personas, más no, porque ahí trabajaban ocho horas, diez horas, dependiendo del movimiento que había [...]; la planta de Guafo funcionaba al mismo tiempo que la de acá, [San Carlos de Corral] porque cuando habian hartas ballenas se venían para acá y cuando pescaban pocas las tiraban ahí, para que las faenaran ahi mismo, entonces no perdian tiempo, porque había que aprovechar la temporada. Los trabajadores eran llevados desde Valdivia. Raúl finaliza su testimonio con una frase muy precisa: la ballena siempre habitó en la isla de Guafo ${ }^{45}$.

En sus inicios, la planta de Guafo era poco más que una instalación costera muy semejante a las desarrolladas para la caza tradicional de ballenas (Quiroz 2012). La planta se fue, sin duda, complejizando en el tiempo. Fue muy afortunado encontrarse con Onofre Almonacid y Bernardino Bórquez en Quellón, Chiloé, y haber podido escuchar sus historias sobre cómo se trabajaba la ballena en Guafo (Fig. 5).

\section{La Caza de Ballenas}

Don Onofre nos cuenta que llegué a conocer cómo se cazan las ballenas [...] arriba del buque había uno, en un barrilito así, arriba en la punta del palo y ese iba dirigiendo con una cosa y el otro, que estaba abajo, también 


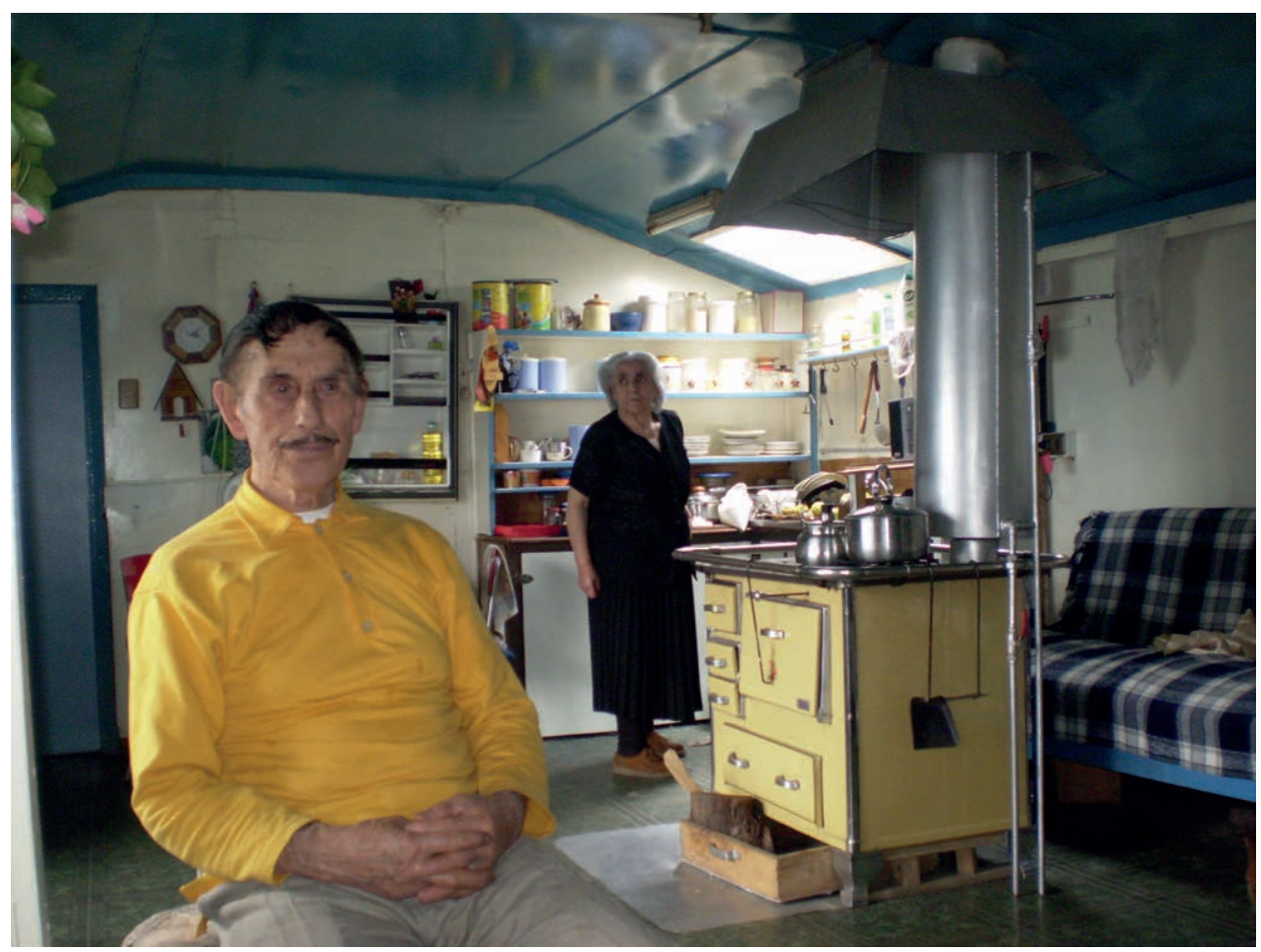

Fig. 5 Don Onofre Almonacid en su casa de Quellón, al fondo su esposa, Amanda Low, 2008 [Foto Paula de la Fuente].

con otra cosa mirando. Cuando se resumía la ballena, disparaba el cañón y lanzaba el arpón con tremendo cabo, así de este grueso, de nylon, ese tremendo rollo, más de doscientos metros, como avanzaba tanto, igual que tirar una bala, antes que se sumerja la ballena llegaba el coso ese y entraba en la ballena $y$ cuando entraba adentro, ese coso de fierro se abría, la misma explosión hacía que se abriera y quedaba hecho un anzuelo por las dos, tres, cuatro patas, entonces la ballena, haga lo que haga, no salía porque tenía un gancho adentro, en el hueso, entonces no salía [...] luego la tiraban, con motor del buque, con el mismo cabo y ahí la amarraban de la parte de la cola a la cabeza con dos cosas grandes, con ganchos con motores igual, y así la llevaban, la llevaban la parte de la cabeza levantada y la cola igual levantada y todo lo que es cuerpo iba en el agua [...] cuando el barco [...] llevaba tres ballenas, daba tres pitos y si daba cuatro pitos eran cuatro ballenas [...] entonces, cuando venía lejos y uno alcanzaba a escuchar el pito, la gente sabía cuántas ballenas traía. Eso lo sé yo porque mi hermano estaba contento cuando había trabajo, cuando había ballenas, había trabajo también ${ }^{46}$.

Don Bernardino agrega que los buques eran sencillitos, lo único que ahí estaba el cañón para tirar el arpón, porque el arpón era tirado con un cañón, un cañoncito chico así, y el proyectil que iba tenía espoletas, era cargado en la punta, entonces llegaba a la ballena y se abría y no salía, tenía patas y se abría y quedaba encarnado en la ballena, y de ahí la ballena empezaba a correr y el buque se dejaba parado de máquinas y que lo remolcara la ballena, y la ballena se cansaba, entonces lo tiraban al lado y lo lanceaban con unas lanzas para desangrarla y para matarla también, después le ponían una bandera a la ballena y la dejaban mar afuera, en tal parte, en tal punto, y cuando ya tenían 3 o 4 las empezaban a buscar y las traían remolcando 
a Guafo, donde se las trabajaba. [...] Los barquitos eran así no más, una cosita sencilla, deben de haber tenido unos treinta metros de eslora, no más tenían, ni eso, [...] tenían buena máquina sí, debe de haber corrido unas doce millas. Eran buques de fierro. Eran barquitos noruegos porque la inscripción del barquito era noruego, el Scott, nombre noruego, el Pengüin, nombre noruego, le decían el Pingüino, igual venía grabado con soldadura, tenía grabado aqui en la parte de la línea de cubierta, en la proa [... ], y el Ballena y el Samson, eran cuatro pesqueros, eran chicos. Venían a veces a Quellón, en Coldita lo vimos siempre ${ }^{47}$.

\section{El Procesamiento de las Ballenas}

Don Onofre no sólo supo cómo se cazaba las ballenas sino también ahí vi cómo se faenaban las ballenas, cómo las cazaban y cómo las llevaban allá, al lugar, porque había una tremenda rampla que habian hecho de cemento con unas canaletas. [...] Cuando llegaba la ballena la tiraban con un motor porque iquién lo podría tirar ese tremendo animal, gigante! y lo tiraban así, lo subían arriba de la rampla esa, de losa, de cemento y ahí lo descuartizaban [...] lo partían con unos mangos, asi con corvo así, unos mangos largos y lo partían y le sacaban pedazos grandes, pedazos grandes que de ahí los arrastraban y lo subian [...] arriba tenian una aguja y como siete calderas grandes, [...] ahí la ensillaban en la aguja, más allá otra aguja y colocaban esos sanchos grandes ahi y de ahí lo subian y lo sacaban arriba en esos salones grandes, [...] y ahí lo tiraban con ganchos, mandaban un ganchazo ahi y lo tiraban al hoyo y eso caía a las calderas abajo, entonces, a una cierta distancia de la carne ponían una plancha de fierro, después de eso volvían a poner todo, tripales y todo, todo; y ahí no quedaba nada, sólo la sangre que caía y ahí iba todo a las calderas, las tripas y todo, a las calderas no más.

47 Entrevista con Bernardino Bórquez, Quellón [Chiloé], noviembre 2008.

48 Entrevista con Onofre Almonacid, Quellón [Chiloé], noviembre de 2008.
Y ahi afuera tenían unas cañerías con llaves, todos los estanques esos, las calderas y ahí cuando ya llenaban hasta arriba, todo, le abrían la llave de calorías, el vapor, y eso empezaba a derretirse en más o menos en una hora, que yo miré todo eso, me acuerdo, yo miraba, como chico es intruso, no me tomaban en cuenta que yo andaba ahi y veía como caía el agua, en más o menos una hora empezaba a caer, ya empezaba a cocerse la carne y empezaba a caer el aceite en una y en la otra y en la otra y en la otra y así, pero distintos aceites. Yo pensaba en mi ignorancia, ¿cómo se clasificaba el aceite bueno, el aceite malo, el aceite que era pa' negocio, el otro que no?, y todo iba saliendo así en las cañerías. Tenían estanques que recibian el aceite de la ballena ${ }^{48}$.

\section{Los Trabajadores de la Planta}

Don Onofre nos cuenta también que en Guafo trabajaba pura gente de acá, de por acá no más, el único de afuera era el administrador, Guillermo Dornes, el señor Billes, él era el patrón, llegaba a veces no más. Se trabajaba en cuadrillas, se juntaban parientes y amigos y se hacían las cuadrillas y se iban unos a hachar, a cortar leña, especialmente a eso. La otra cuadrilla era para descuartizar la ballena, las otras cuadrillas eran para acarrear la leña de dónde caían del cerro, para llevarla a la administración, a las calderas. Las otras cuadrillas eran para vaciar esos tambores, salian todos esos siete tachos de chicharrones, habia que vaciar esos tachos y limpiar y todo eso lo hacía otra cuadrilla [...] limpiar los tachos, sacar toda esa gordura quemada y cocida, que ya no tenía más grasa, irla a botar lejos con carretillas, con carros y limpiar los tachos y volverlos a las calderas [...] y después la otra cuadrilla, que era para cortar la ballena y después los otros para acarrear la gordura para arriba, llevarla a las calderas [...] y así todo se iba haciendo en cuadrillas,

49 Entrevista con Onofre Almonacid, Quellón [Chiloé], noviembre de 2008.

50 Entrevista con Bernardino Bórquez, Quellón [Chiloé], noviembre de 2008. 
la cuadrilla más grande era donde trabajaba yo, era de veintiún hombres. En la cuadrilla mía, estaba yo, ahí éramos todos familia, eran primos, tios, suegros ${ }^{49}$.

Don Bernardino relata que en Guafo trabajaba casi pura gente de Quellón, todos los de Quellón trabajaban ahí [...] también la gente de Coldita, algunos trabajaban en descuartizar la ballena, que era todo a puro machete no más, y el resto trabajaban en la leña, la leña era para alimentar las calderas ${ }^{50}$. Uno de los entrevistados por Navarro (2008) en Melinka informa que en la isla de Guafo había fabrica ballenera [...] mi papá trabajaba en la isla [...entró] como a los 18 años [y estuvo] seis, siete años, hasta que se definió la ballenera, agregando que algunos trabajadores de aqui de la isla de Melinka, se iban a trabajar a Guafo, yo me acuerdo ${ }^{51}$. La mayoría de los trabajadores de Guafo provenían de las islas situadas en riberas del golfo del Corcovado.

\section{La "escuela ballenera" de Guafo}

Los testimonios nos hablan de la existencia de una "escuela ballenera" en Guafo. En dicho establecimiento habían hecho sus primeras armas el capitán Humberto Olavarría, luego comodoro de la flota de la Compañía Industrial, y el maestro descuartizador Isaías Jaramillo, quién montó la sección de descuartizamiento en la planta de Bajo Molle, Iquique en 1956. Don Bernardino Bórquez relata que había un arponero que era de la Punta Lapa, de Quellón, parece que era Barría, Olavarría, [...] era el que disparaba el arpón para las ballenas, era uno de los buenos porque le hacía la competencia a los noruegos ${ }^{52}$.

Don Juan Vera indca que mi padre trabajó en la ballenera en Guafo y después, cuando terminó, cuando terminó la ballenera en Guafo, la ballenera se trasladó a Quintay [...] años después vino un contratista buscando a la gente chilota, que era experta en descuartizamiento

51 Testimonio de descendiente directo de un trabajador de la planta ballenera de isla de Guafo (Navarro 2008: 71).

52 Entrevista con Bernardino Bórquez, Quellón [Chiloé], noviembre de 2008.

53 Entrevista con Juan Vera, Quellón [Chiloé], noviembre 2008. de ballena, en ese tiempo, me acuerdo yo, de Don Zoilo Barría, Eulogio Vera que se llamaba mi padre, de Don Vicente Díaz, y otros tantos caballeros que en este momento no me recuerdo [...] ellos eran expertos en el trabajo de la ballena [...] y mi papá le dijo al contratista que vino, yo ya estoy avanzado de edad y no puedo ir, ¿por qué no va uno de mis hijos en lugar mío? Bueno, dijo el contratista, ningún problema. Y ahí yo tuve la oportunidad de ir a trabajar a Quintay. Mi papá me conversaba que la tecnología en cuanto a faena de la ballena no era la misma que en Quintay, ya se reformó la técnica, fueron otras máquinas más modernas, pero allá no, se trabajaba a fuerza de brazos no más, a fuerza de pulso no más ${ }^{53}$.

Don Pedro Vera señala que a su hermano lo buscaron, lo conocían de la isla Guafo donde había trabajado antes, porque en Guafo había una empresa ballenera, lo conocían y se lo llevaron a Valparaíso, a Quintay, a trabajar allá, tenía 50 años cuando lo llamaron para trabajar en la Compañía Industrial Ballenera [...] su hermano se llamaba Federico Vera, era 'descuerador', maestro descuartizador, se llevaron también a otros, a Carlos Aravena, a Isaías Jaramillo. Don Pedro también nos habla de los vapores cazadores: los buques en Guafo eran lo mismo que en Valparaíso, cazadores, claro que en Valparaíso los barcos eran más modernos, no los antiguos que trabajaron en Guafo [...] a Valparaíso llegaron después barcos petroleros, con motores diésel, los de Guafo tenían calderas a puro carbón, a Valparaíso llegó solo uno de esos barcos, de Guafo de 'reliquia' y se lo dieron a un capitán de Chiloé para que lo trabajara, era Humberto Olavaria Gallardo, era de Quellón, de la zona de Punta Lapa, ahí vivía. Después fue comodoro de toda la flota de Valparaíso ${ }^{54}$. Don Eduvino Cárcamo cuenta que no conoce la Isla Guafo, pero Juan Bautista Uribe, un tío, trabajó en Guafo con los hermanos Díaz, Jerónimo, Gabriel y Oscar, y también con Zoilo

54 Entrevista con Pedro Vera, Puerto Montt, diciembre de 2008

55 Entrevista con Eduvino Cárcamo, Quellón [Chiloé], noviembre de 2008.

56 Entrevista con Ricardo Saldivia, Quellón [Chiloé], noviembre de 2008 


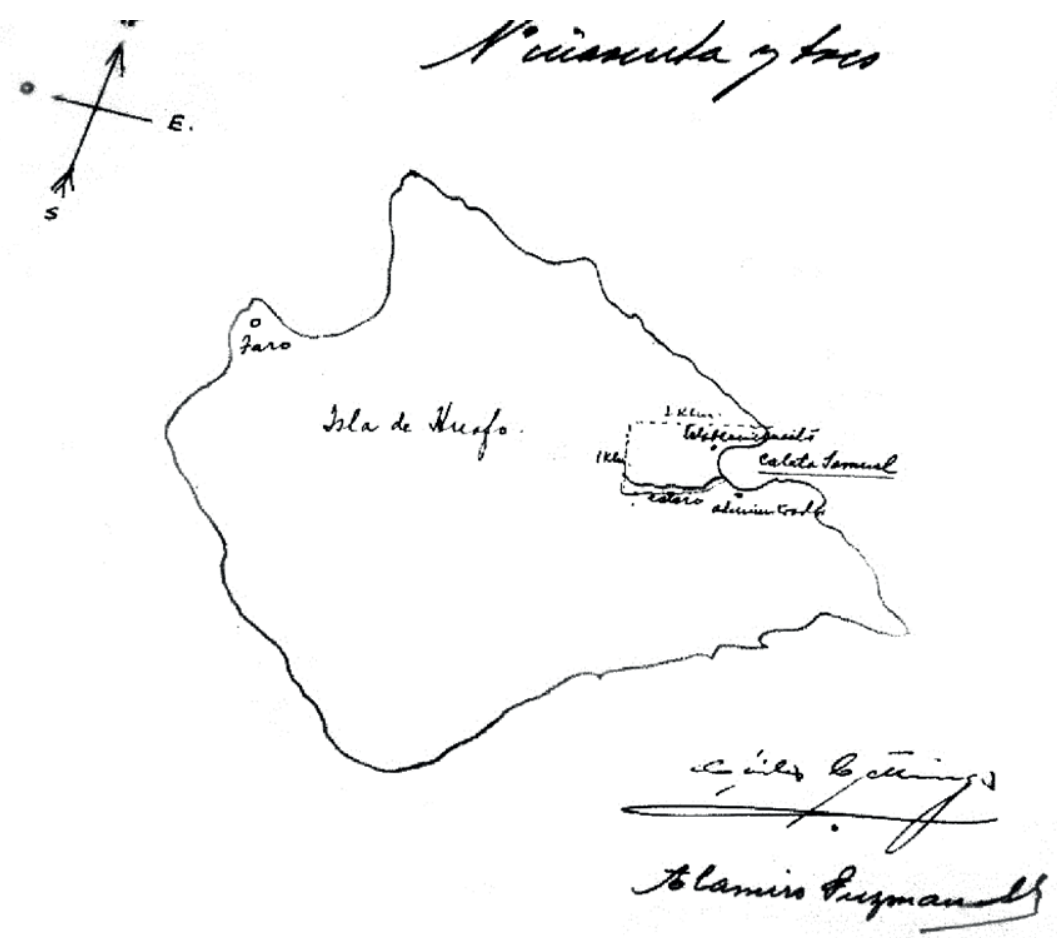

Fig. 6. Croquis de la ubicación del establecimiento ballenero en caleta Samuel, isla Guafo [Escrituras Públicas de Santiago [José Vicente Fabres], 1925, V. 3233, Protocolo n 43, 18 de abril de 1925. Archivo de la Administración del Archivo Nacional [Santiago, Chile].

Barría $^{55}$. Don Ricardo Saldivia relata que su padre se llamaba Ramón Saldivia, trabajó en Guafo, también su tío Guillermo y sus primos Juan y Carlos Saldivia, todos de Quellón. El papá se iba a la planta de Guafo, andaba afuera un mes o más. Para ir y volver había locomoción de barcos, trabajaba en el monte cortando leña para las calderas de Guafo, ahi trabajaba mucha gente $^{56}$.

Isaías Jaramillo nos contaba en Quintay que su padre Isaías Jaramillo Pérez, trabajó en la isla de Guafo primero, cuando era joven, de ahí la INDUS lo trasladó a Quintay, ahi estuvo mucho más tiempo y después lo trasladaron a Bajo Molle, Iquique [...] cuando la ballenera se instaló en Guafo necesitaban gente para el trabajo y la única gente que ellos conocían

57 Entrevista con Isaías Jaramillo Elgueta, Quilpué, febrero de 2010.

58 Entrevista con Guillermo Lobos, Quellón [Chiloé], noviembre de 2008.

59 Escrituras Públicas de Santiago [José Vicente Fabres], 1925, Protocolo $n^{\circ} 43,18$ de abril de 1925, V. 3233. era de ahí, de Chiloé, y empezaron a faenar la ballena en Guafo, hasta un buque fábrica tenía la INDUS, mi papá anduvo también en ese buque fábrica y se especializó, fue uno de los primeros balleneros, empezó a gustarle esto y llegó a ser jefe de sección, entonces él mismo especializó a los chilotes a trabajar la ballena ${ }^{57}$. Guillermo Lobos cuenta que Isaías Jaramillo, un tío mío, estuvo trabajando en Guafo, luego se fue a Quilpué. Trabajó toda su vida en la ballenera, primero en Guafo, luego en Quintay. Después volvía a Quellón a buscar gente para la ballenera [...] traía unos cincuenta hombres para la faena por una temporada de seis meses. También estuvo en Iquique, cuando se armó la planta de Bajo Molle $e^{58}$.

Archivo de la Administración del Archivo Nacional [Santiago, Chile].

60 Escrituras Públicas de Santiago [José Vicente Fabres], 1925, n 399, 18 de abril de 1925, V. 3233, fs. 338v339. Archivo de la Administración del Archivo Nacional [Santiago, Chile]. 


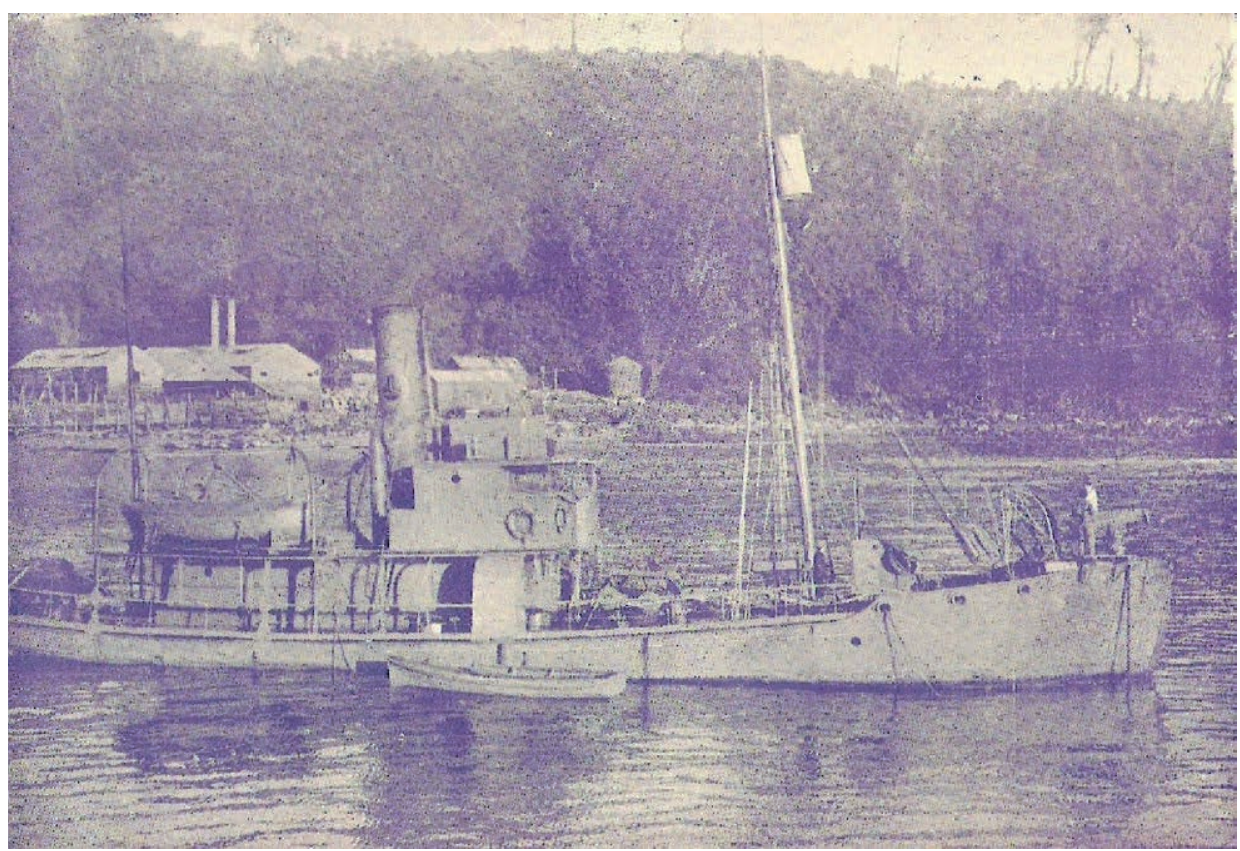

Fig. 7. En primer plano el INDUS 2, al fondo la planta ballenera de Guafo [Foto Indus 1938]

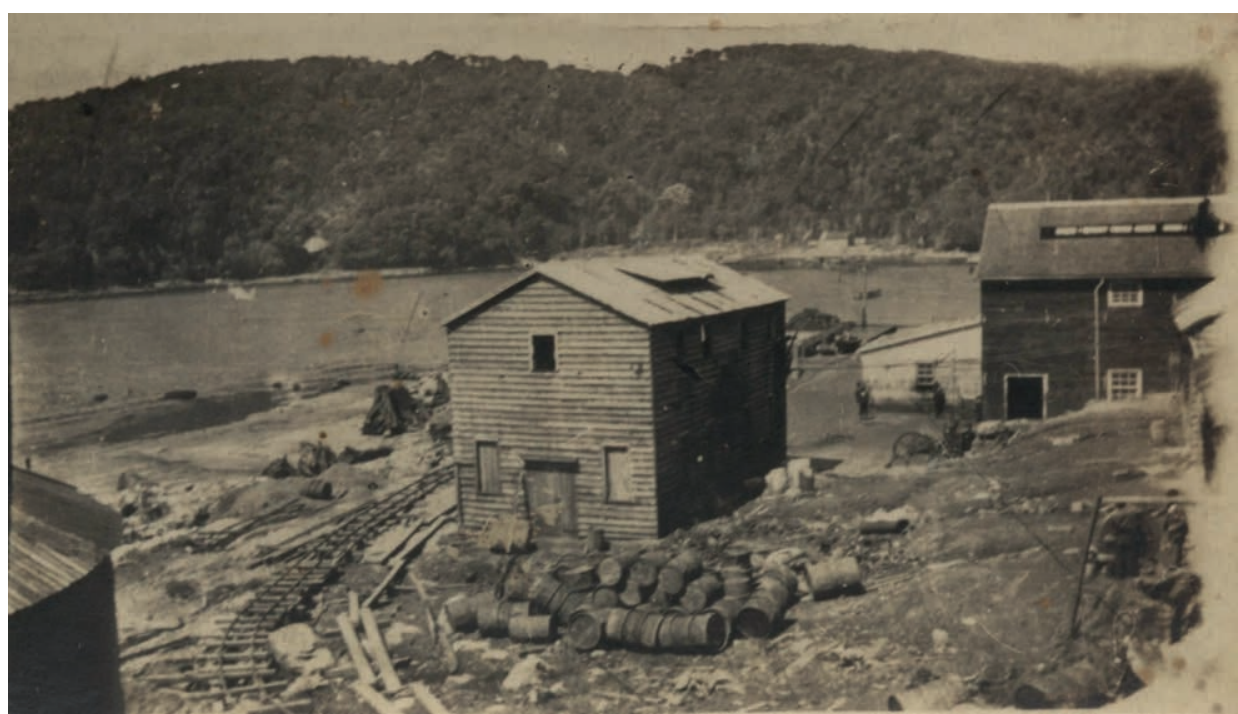

Fig. 8. Una vista de la planta ballenera de Guafo [Foto gentileza de Fernando Oettinger].

La planta de isla Guafo es una verdadera "escuela ballenera", donde muchos chilotes, sobre todo de Quellón hacia el sur, aprenderán el oficio ballenero y luego se transformarán en maestros para difundirlo en otros lugares de Chile.

Contactos con las imágenes
La primera imagen que nos interesa considerar es un croquis de la isla Huafo [...] en el que se demarca la parte de suelo dada en arrendamiento y que indica además el lugar donde se construirá la Casa de la Administración, que se encuentra protocolizado como anexo ${ }^{59}$ al segundo contrato de arriendo realizado en 1925 entre Carlos Oettinger y Alamiro Guzmán ${ }^{60}$. 


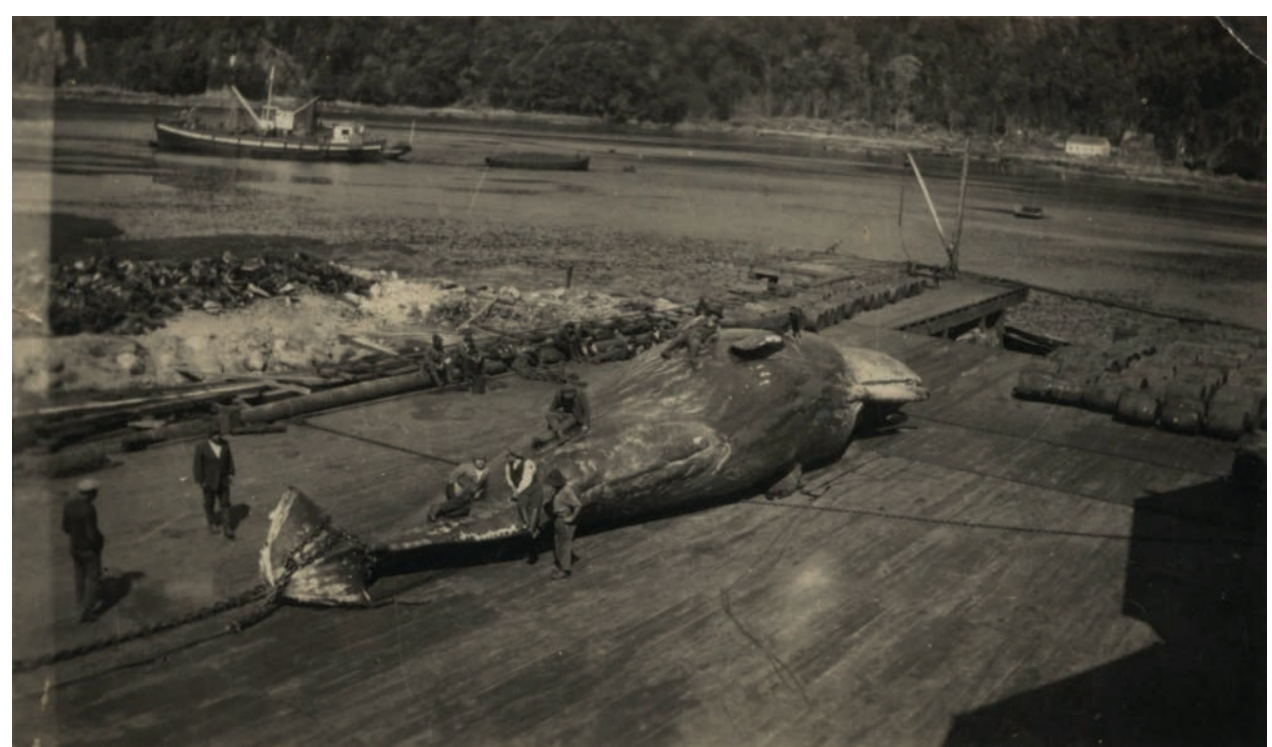

Fig. 9. Una vista de la plataforma de descuartizamiento y rampa de la planta ballenera de Guafo [Foto gentileza de Fernando Oettinger].

En el croquis se indica que el establecimiento ballenero se encuentra al norte de la desembocadura del estero Samuel y la casa de la administración al sureste (Fig. 6). Si consideramos la morfología de la ribera norte de la desembocadura tenemos que las estructuras del establecimiento se construyen con una orientación noreste.

Hemos reunido tres fotografías históricas de la planta ballenera de Guafo en la década del 30', que permiten generar una pequeña descripción de sus estructuras.

En la Fig. 7 se observa, en un segundo plano, una vista general de los edificios de la planta ballenera de Guafo que sigue la línea de costa (Fig. 7 y 8). Separados por la chimenea del buque se ve a la derecha una estructura circular (A) que corresponde,
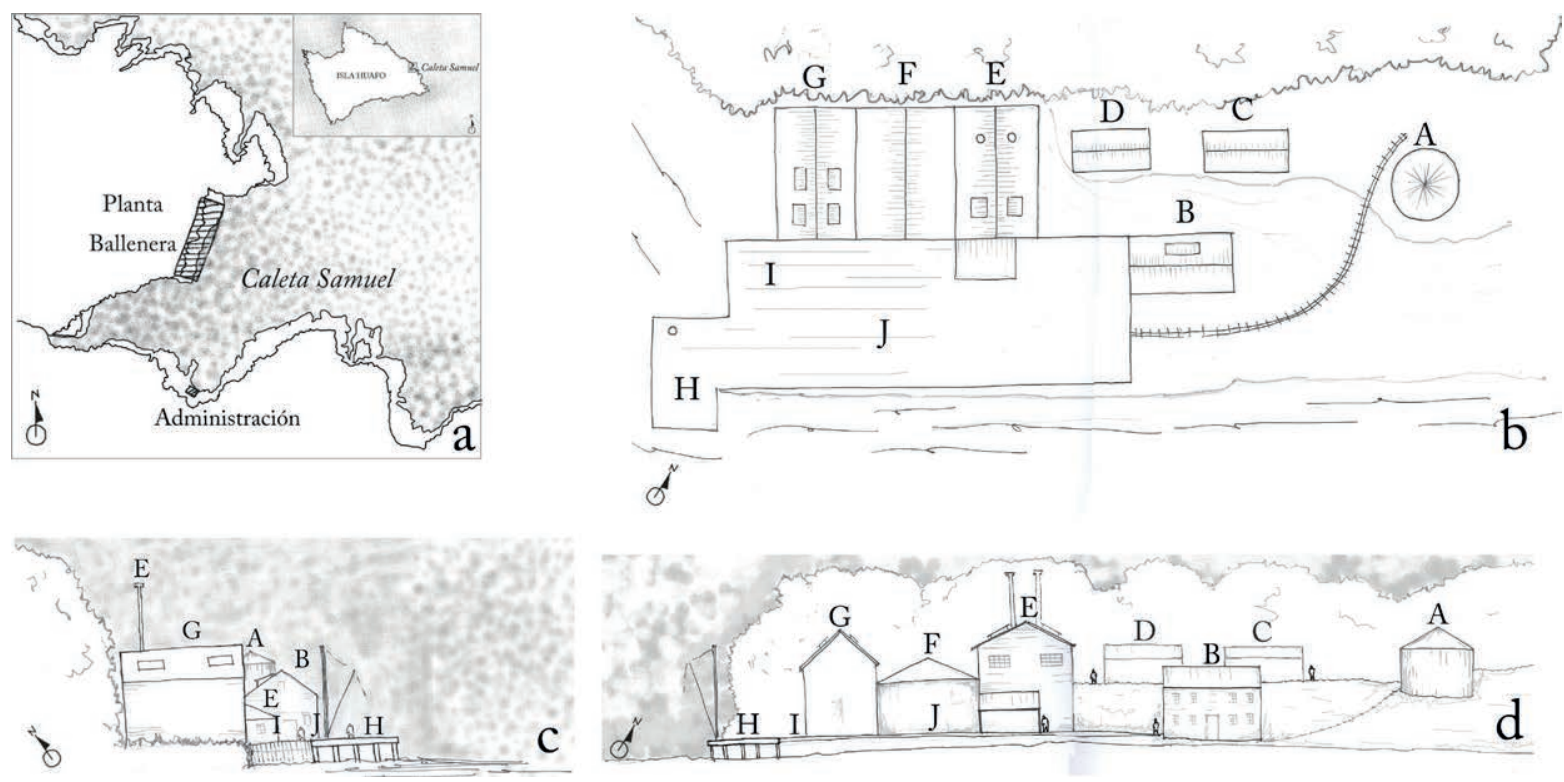

Fig. 10 a) emplazamiento, b) plano, c) vista frontal y d) vista lateral de Planta Ballenera de Guafo [Croquis de Paula de la Fuente, basado en las fotografías publicadas como Figuras 6-8] 
seguramente, a un estanque de aceite, dos edificios de dos pisos (B y C) y otro hacia el cerro (D). A la izquierda, se observan otros tres edificios (E, F, G), uno de las cuáles (E), que debería ser la Fábrica de Aceite, muestra dos chimeneas. Delante de los edificios E-G están, aunque en la fotografía no se distinguen claramente, el muelle $(\mathrm{H})$, la rampa (I) y la plataforma de descuartizamiento (J) - Figs. 9 y 10 .

En la Fig. 8 se muestra una vista oesteeste de las construcciones situadas en la derecha de la Fig. 7. En el centro se observa el edificio B, a la izquierda la cubierta del estanque de aceite o edificio A, a la derecha parte de las construcciones $\mathrm{D}$ y E y junto a ellas un sector de la plataforma de descuartizamiento y el muelle con su grúa. Se ve, además, una línea de rieles para carros entre el estanque de aceite y el edificio $\mathrm{B}$ y varios barriles de aceite amontonados. Al fondo se distingue el edificio de la administración (K), que se encuentra en la ribera sur de la caleta Samuel.

En la Fig. 9 se ve en primer plano la plataforma de descuartizamiento $(\mathrm{J})$, con su cubierta de madera y una ballena de barbas preparada para ser procesada, el muelle (H) y la rampa (I), con su grúa. Tanto en la plataforma como en el muelle se ven barriles de aceite agrupados ordenadamente. En el agua uno de los vapores cazadores y una lancha. Al fondo, hacia la derecha, se ve el edificio de la administración de la planta (K).

Las fotografías nos ayudan a elaborar una lámina resumen que nos permite mostrar el emplazamiento, plano y croquis con dos vistas de la Planta Ballenera de Guafo. Son vistas hipotéticas pues no tenemos todas las imágenes necesarias para una representación más precisa del conjunto de edificios que la constituyen. Si volvemos a mirar la Fig. 4 tenemos una vista cercana de la cubierta de madera de la plataforma de descuartizamiento,

61 Entrevista con Ricardo Saldivia, Quellón [Chiloé], noviembre de 2008.

62 AWSANZ (Archaeology of Whaling in Southern Australia and New Zealand) es un proyecto de colaboración internacional iniciado y dirigido por Susan Lawrence, de La Trobe University, en Melbourne, y Mark Staniforth de Flinders University, en Adelaide. Su tema es la arqueología e historia de la industria ballenera colonial de Australasia.

63 LASHIPA(Large-Scale Historical Exploitation of Polar Areas) es un proyecto de investigación histórico y arqueológico a la izquierda una vista parcial de $\mathrm{E}$ y a la derecha del edificio D.

\section{Contacto con las ruinas}

Desafortunadamente no pudimos conocer Caleta Samuel, en isla Guafo, y por lo tanto, tampoco estar ahí y "sentir" en las ruinas la presencia de los balleneros. Prácticamente no quedan vestigios de la antigua planta, que había dejado de funcionar en la segunda mitad de la década de 1930, pero lo poco que hay testifica su presencia (Figs. 11 y 12). Uno de sus visitantes señala que la única evidencia conspicua que permanece es el crecimiento de vegetación secundaria en unas pocas hectáreas alrededor de la caleta, donde los árboles fueron talados para combustible (Clark et al., 1984: 25). Don Ricardo Saldivia, que estuvo en caleta Samuel hace unos quince años [c. 1998] cuenta que vio una plancha de cemento de unos 50 metros cuadrados, donde faenaban la ballena. Quedaban unas partes donde hacían el fuego para las calderas y unos pedazos de caldera ${ }^{61}$.

Contamos, sin embargo, con un conjunto de fotografías realizadas por personas que estuvieron ahí y registraron parte de sus ruinas (Moulián \& Lema, 2013).

Se ha avanzado mucho en el estudio arqueológico de la industria ballenera en diversas épocas y lugares. Sólo como ejemplo podemos mencionar los estudios sobre establecimientos balleneros del siglo XIX en Australia y Nueva Zelanda (Pearson, 1985; Mcllroy, 1986, Gibbs, 1995; Lawrence \& Staniforth, 1998; Patterson, 2006; Pricket, 2002; Gibbs, 2010), varios de ellos realizados en el marco del proyecto AWSANZ ${ }^{62}$. Otra iniciativa interesante es el proyecto LASHIPA $^{63}$, que ha generado varias publicaciones (Gustafsson, 2008, 2010; Hacquebord, 2008,

que busca explicar el desarrollo de la explotación en gran escala de los recursos naturales en las áreas polares desde el siglo XVII hasta nuestros días y las consecuencias que tuvo ese desarrollo en la situación geopolítica y en el ambiente natural. Las instituciones que participan son el Arctic Centre, University of Groningen, Holanda; Division of History of Science and Technology, Royal Institute of Technology, Suecia; Industrial Archaeology, Michigan Technological University, Estados Unidos; Russian Academy of Sciences, Moscú, Rusia; European University, St. Petersburg, Rusia. 


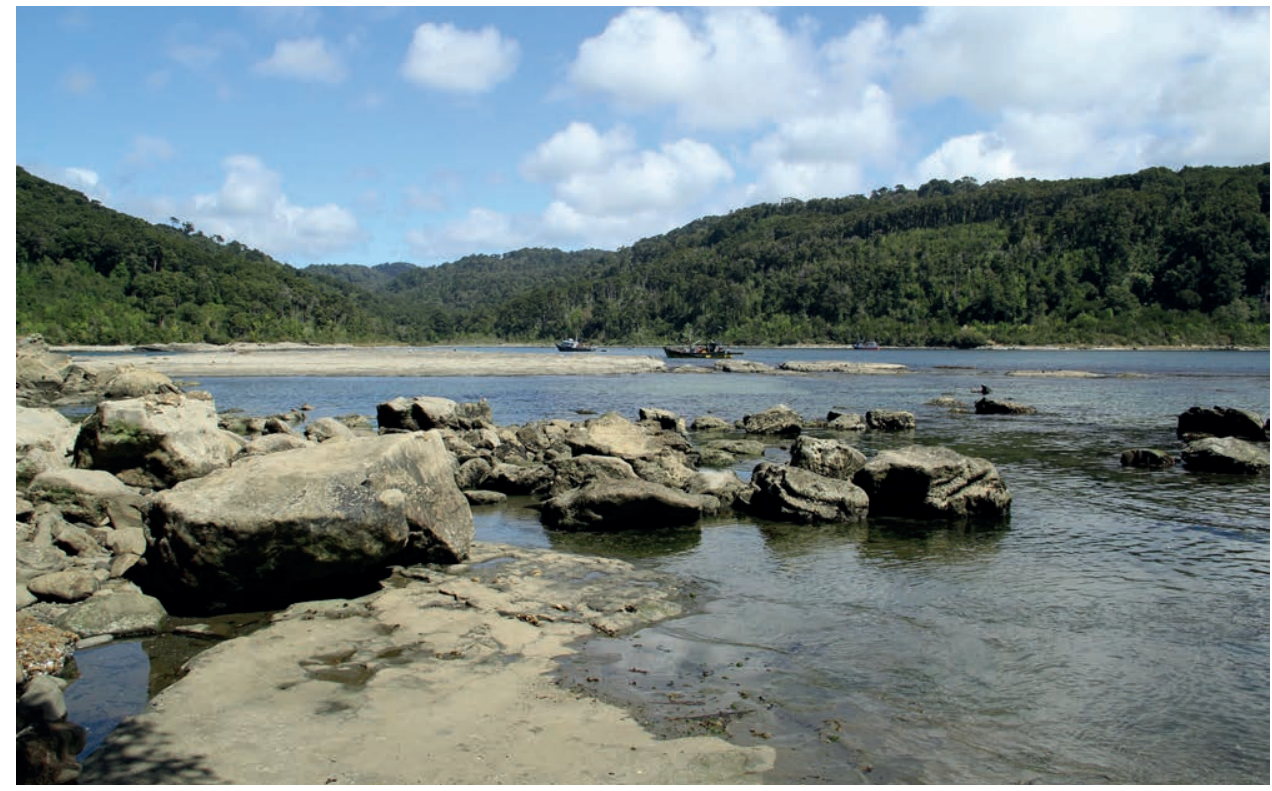

Fig. 11. Caleta Samuel en isla Guafo, a la derecha emplazamiento de Ballenera de Guafo. [Foto gentileza de Carolina Lema]

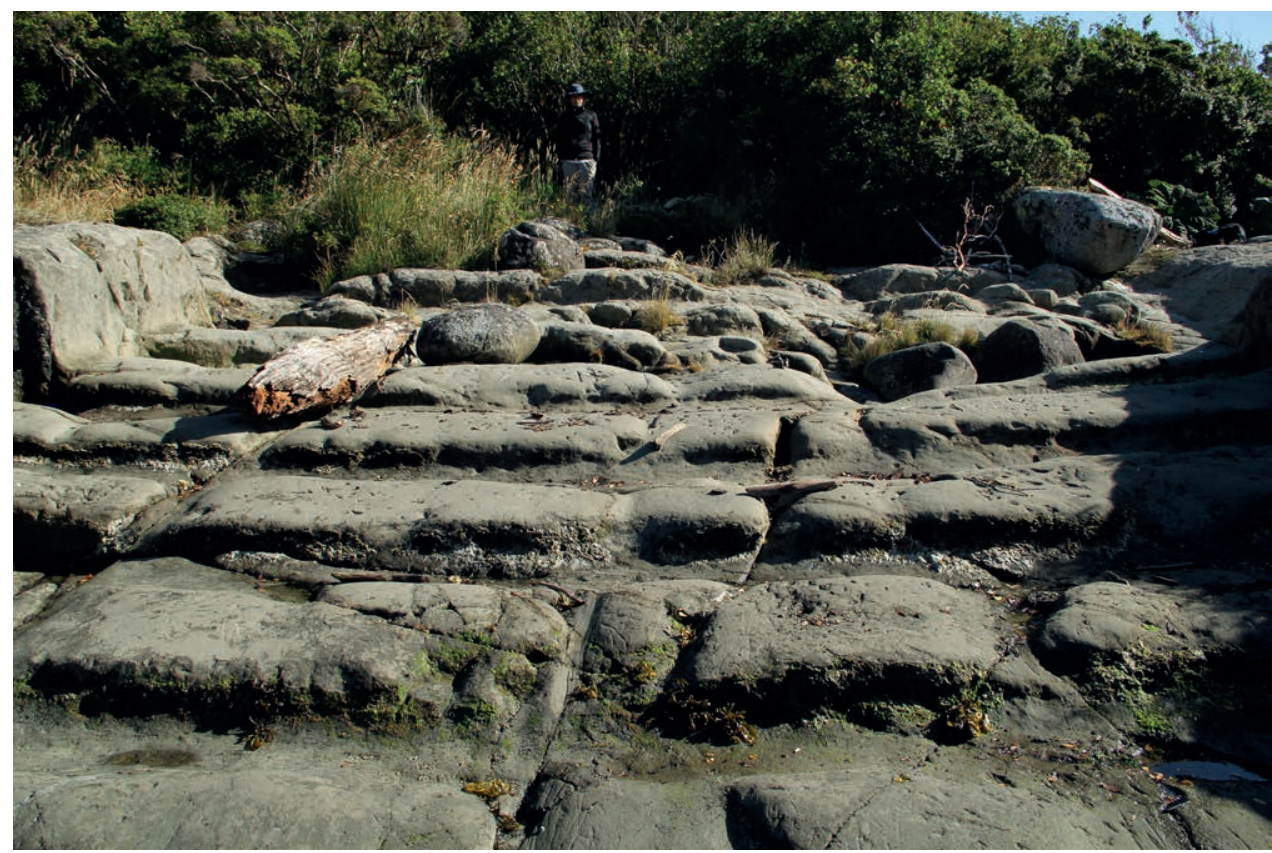

Fig. 12. Estructura que soportaba la rampa de la planta ballenera de Guafo. [Foto gentileza de Carolina Lema]

2010), aunque lo más relevante aún está por aparecer. Uno de sus sub-proyectos, denominado La explotación de los recursos naturales por la industria ballenera en los inicios del siglo XX, considera estudiar, de manera comparativa, cuatro estaciones balleneras que estuvieron operativas durante las primeras décadas del siglo $\mathrm{XX}$, tal como la planta ballenera de Isla Guafo: Finneset, 
en Spitsbergen y Walrus Bay, en Bjørnøya, ambas islas situadas en el archipiélago de Svalbard, Noruega; Prince Olav Harbour, en Georgia del Sur, y Signy Island, Orcadas del Sur, grupos de islas cercanas a la Antártica, dependientes en la actualidad de Gran Bretaña. Mientras no tengamos los resultados de estos trabajos, disponemos de un conjunto reducido de publicaciones sobre estudios arqueológicos realizados en ruinas de las estaciones balleneras del siglo XX, destacándose, sin duda, el completo estudio sobre las plantas balleneras en la isla Georgia del Sur realizado por B. Basberg (2004) y una serie de trabajos monográficos sobre las estaciones balleneras Balaena en Newfoundland, Canadá (McGonogle \& Staniforth, 2007), Point Cloates, en Norwegian Bay, Australia (Stanbury, 1985), y Whangamumu, en Bay of Islands, Nueva Zelanda (Goddard, 2010).

Sería de interés realizar un trabajo arqueológico histórico que explore las ruinas de la planta y encuentre los elementos que nos permitan reconstruir su fisonomía y entender algunas de las modificaciones que ha experimentado a través del tiempo. Por razones tectónicas algunos restos de las construcciones de la planta se encuentran hoy bajo el agua, otros fueron destruidos por el maremoto de 1960, moviéndolos de sus emplazamientos originales y algunos severamente afectados por más de setenta años de abandono. Cuando hablamos de arqueología histórica nos estamos refiriendo al estudio de las "materialidades modernas", desde "las pequeñas cosas olvidadas" a los "complejos tecnológicos mayores", y desde "los objetos únicos" hasta "los grandes conjuntos dispares"64. Es una tarea de gran magnitud que, desafortunadamente, no pudimos abordar en el marco de este trabajo.

La mayoría de las plantas balleneras en Chile están muy destruidas, incluso algunas fueron desmanteladas para equipar otras que se estaban construyendo. La planta de Guafo está entre las más destruidas y su presencia es prácticamente invisible. Entre las más nuevas se conservan algunas

64 Para una presentación contemporánea de la arqueología histórica ver Gilchrist (2005). World Archaeology le dedica un número especial a la arqueología histórica [2005, 37(3)]. Hay algunas revistas especializadas tales como International Journal of Historical Archaeology [Springer], Historical Archaeology [The Society for Historical Archaeology] y de sus construcciones pero el deterioro ha sido muy rápido. La planta de Bajo Molle, al sur de Iquique, la más nueva de todas, es la que mejor se conserva pero está en peligro como las anteriores. En la planta ballenera de Quintay se han implementado proyectos que han logrado recuperar algunas de sus estructuras y está en estudio su declaratoria de monumento histórico. Pero en ninguna se ha realizado trabajos arqueológicos sistemáticos que permitan "reconstruirlas" desde las ruinas. Esperamos que este tipo de estudios pueda iniciarse en Chile, aunque sea logísticamente complejo en lugares tan apartados como isla Guafo.

\section{CONCLUSIONES}

La existencia de una planta ballenera en isla Guafo ha sido establecida anteriormente (Navarro, 2008, Quiroz 2010a, 2010b, 2011; de la Fuente \& Quiroz, 2011), pero los trabajos aportan datos muy generales y la información no es muy precisa. Por ejemplo, Navarro señala que la planta ballenera ubicada en isla Guafo [...] fue establecida en caleta Samuel, aproximadamente en 1906 [...y] funciona hasta la década del 60 (2008: 70). Estos datos no son correctos pues hemos mostrado que fue construida en 1922 y funcionó solo durante dieciséis años, hasta que fue cerrada, desmantelada y abandonada en 1937. Fue administrada secuencialmente por cuatro sociedades, la Sociedad de Pescadores Chile y Noruega [1922-1923], Sociedad de Pesca Thomassen y Compañía [1924], Sociedad Ballenera de Corral [1925-1935] y Compañía Industrial [1936-1937]. Fue abandonada debido a que sus últimos dueños decidieron experimentar en la caza pelágica e, incluso, algunos de sus trabajadores fueron contratados para operar en el buque factoría INDUS BF (Quiroz \& de la Fuente, 2012).

Navarro entrega un dato interesante que no pudimos corroborar: los datos censales de 1930 , señalan que esta isla [tiene] una población de 105 hombres y 16 mujeres, que constituyen en su totalidad la población de los trabajadores de

Australasian Historical Archaeology [Australasian Society for Historical Archaeology], entre otras.

65 Entrevista con Ricardo Saldivia, Quellón [Chiloé], noviembre de 2008.

66 Entrevista con José Barrios, Quintay [Valparaíso], enero de 2010 . 
la sociedad ballenera (2008: 70). Esta es una información que merece ser revisada. Nos habla de una población aproximada de 120 personas, en su mayoría hombres, trabajando en la planta de Guafo en 1930. No tenemos información sobre la participación de mujeres en las actividades balleneras, pero Don Ricardo Saldivia nos cuenta que en caleta Samuel los pescadores hicieron una cueva al frente de donde se varaba la ballena [...] hay varios muertos en la cueva esa, son del tiempo de la ballenera, está una señora que murió en Guafo con su hijo recién nacido. Era un matrimonio. En Guafo a todos le daban casas $y$ ahí vivían ${ }^{65}$.

La planta debe ser considerada una verdadera escuela ballenera pues muchos trabajadores aprendieron ahí el oficio, conocimiento que luego fue difundido en las plantas construidas posteriormente como Quintay y Bajo Molle. Son numerosos los testimonios que hablan de este proceso.

Esta secuencia queda claramente demostrada en las palabras de un ex ballenero de Quintay. José Barrios relata que la ballenera de Quintay fue un barco primero, un barco de esos mercantes, le hicieron una plataforma arriba, con todos los estanques de aceite $y$ todas esas cuestión, lo hicieron y cazaban ballenas en el mar, entonces, [pero] como era muy angosto, pudieron varias veces darse vuelta, darse vuelta porque se les iba la ballena para el lado [...], entonces desarmaron la ballenera, el barco ese lo deshuesaron, como decimos nosotros, le sacaron todo y la hicieron en esa isla, la ballenera, en Guafo. Pero los barcos en vez de pillar más al sur la ballena, venían más al norte a pillarla, mientras más al norte venían, más ballenas encontraban y se cambiaron de allá, se cambiaron de esa isla a Corral, a la vuelta de Corral, a una parte que se llama Amargos [donde] están las plataformas que hicieron todavía ahí, pero trabajaron poco tiempo [...], siempre los barcos venían a pillar las ballenas pa'l norte, siempre tirando al norte, porque la ballena se iba al sure y duraba poco al sure y se venía al norte. De ahí de Corral se vinieron para acá, a Quintay ${ }^{66}$. La secuencia histórica real es Corral-Guafo-Buque Factoría-Quintay, no la de José en su relato fundacional, Buque Factoría-Guafo-CorralQuintay. Sin embargo, el relato de José ilustra la intención del narrador, despreocupado de lo que podríamos llamar "realidad histórica", de mostrar el desplazamiento de un conocimiento ballenero desde el sur hacia el norte, siguiendo el movimiento de las ballenas.

\section{AGRADECIMIENTOS}

La información utilizada para escribir este trabajo fue reunida en el marco de los proyectos de investigación Fondecyt 1080115 La cacería de ballenas en las costas de Chile: una mirada desde la antropología y Fondecyt 1110826 Antropología e historia de la industria ballenera en Chile (1936-1983). Mis reconocimientos a Paula de la Fuente por compartir sus entrevistas y dibujos; a Javiera Ávila, Pía Bastidas y Nicolás Rosales por la revisión del Archivo del Conservador de Bienes Raíces de Valdivia; a Irene Aguilar Thomassen por la hermosa imagen de su abuelo $\mathrm{T}$. Thomassen en Guafo; a Fernando Oettinger por las fotografías históricas de la planta ballenera de Guafo y del buque Penguin y a Iñaki Moulián y Carolina Lema por las fotografías de sus ruinas.

\section{BIBLIOGRAFÍA}

Aagard, B. (1930). Fangst og Forskning i Sydishavet. Oslo: Gyldendal Norsk Forlag.

Aguilar, A. (1986). A Review of Old Basque Whaling and its Effect on the Right Whales (Eubalaena glacialis) of the North Atlantic, Report of International Whaling Commission, Special Issue 10, 191-199.

Allen, H. (1923). Commercial and industrial schemes in Valdivia and districts. In W. F. V. Scott (editor) Report on economic and commercial conditions in Chile (pp. 46-48). London: Department of Overseas Trade, Majesty's Stationery Office.

Anónimo (1923). Fra Chilikysten. Norsk Hualfangst-Tidende, 12 (10): 120

Azpiazu, J. A. (2000). Balleneros vascos en el Cantábrico. San Sebastián: Ttarttalo.

Baker, C. S. \& Clapham P. J. (2002). Marine mammal exploitation: whales and whaling. In I. Douglas (Ed.) Encyclopedia of global environmental change, 3: 
Causes and consequences of global environmental change (pp. 446-450). Chichester: John Wiley \& Sons, Ltd.

Basberg, B.L. (2004). The shore whaling stations at South Georgia: a study in Antartic industrial archaeology. Oslo: Novus Forlag.

Basberg, B.L. (2008). Hegemonic transition: American and Norwegian whaling in the $19^{\text {th }}$ and $20^{\text {th }}$ century. International Journal of Maritime Studies, 20 (2), 201-222.

Bøgen, H. S. I. (1948). A/S Framnaes Mek Vaerksted, 18981948. Oslo: Dreyers Forlag.

Brown, S.G. (1976). Modern whaling in Britain and the northeast Atlantic Ocean. Mammal Review, 6 (1): 25-36.

Carreño, G. \& Espinoza, A. (2012). El arpón se queda en la familia: la ballenera Macaya en el golfo de Arauco. In G. Adomilli, L. D'Ambrosio, G. Carreño \& F. Miller (Eds.) Povos e coletivos pesqueiros (pp. 67-92). Río Grande: Editora da FURG.

Cartes, A. (2009). Los cazadores de Mocha Dick. Balleneros chilenos y norteamericanos en el sur del océano de Chile. Santiago: Pehuen.

Clark, G.S., von Meyer, A. P., Nelson J. W. \& Watt. J. N. (1984). Notes on soon shearwaters and other avifauna of the Chilean offshore island of Guafo. Notornis 31, 225-231

Davis, L.E., Gallman, R.E. \& Gleiter, K. (1997). In pursuit of Leviathan: technology, institutions, productivity and profits in am,erican whaling, 1816-1906. Chicago: The University of Chicago Press.

De la Fuente: \& Quiroz, D. (2011). Los chilotes en la ballenera de Quintay. Revista Chilena de Antropología 24 (2), 171-191.

Det Norske Veritas (1913) Register over Norske Skiber. Christiania (Oslo): Trykt I Carl C Werner \& Comps.s Bogtrykkeri

Du Pasquier, J. T. (2000). Les baleiniers basques. Paris: SPM Editions.

Duque, D. (2012). Ecos de la Presencia. Cultura y Memoria al Borde del Mar. La Ballenera de Quintay en Imágenes. Tesis para optar al Grado de Magister en Antropología, Escuela de Antropología, Universidad Academia de Humanismo Cristiano.

Ellis, R. (1991). Men and whales. New York: Alfred A. Knopf. Fanning, E. (1833). Voyages around the World. New York: Collins \& Hannay

Gibbs, M. (1995). The historical archaeology of shore based whaling in Western Australia, 1836-1879. Thesis Ph D, University of Western Australian.
Gibbs, M. (2010). The shore whalers of Western Australia. Historical archaeology of a maritime frontier. Sidney: Sidney University Press.

Gil, G. J. (2010). Etnografía, archivos y expertos. Apuntes para un estudio antropológico del pasado reciente. Revista Colombiana de Antropología, 46(2), 249-278.

Gilchrist, R. (2005). Introduction: scales and voices in world historical archaeology. World Archaeology, 37(3), 329-336.

Goddard, M. (2010). Whangamumu Whaling Station, Bay of Islands. Wellington: New Zealand Department of Conservation.

Gustafsson, U. (2008). Modern Whaling Industry in Spitsbergen as a tool for territorial claiming and national sovereignty strives. Patrimoine de l'Industrie: Resources, Pratiques, Cultures/Industrial Patrimony: Resources, Practices, Cultures, 19, 17-24.

Gustafsson, U. (2010). Industrialising the Arctic: Settlement design and technical adaptations of modern whaling stations in Spitsbergen and Bear Island. In J. E. Ringstadt (Ed.) Whaling \& History III (pp. 45-59). Sandefjord, Kommandør Chr. Christensens Hvalfangst Museum.

Guzmán, J. (2006). Whales and whaling in Chile. In J.E. Ringstad (Ed.) Whaling and History II. New perspectives (pp. 65-75). Sandefjord: Kommandør Chr. Christensens Hvalfangst Museum.

Hacquebord, L. (2003). English and dutch whaling trade and whaling stations in Spitsbergen (Svalvard) before 1660. International Journal of Maritime History, 15, 117 134.

Hacquebord, L. (2008). Dutch Whaling and Whaling Sites in the Arctic. In M. Schillat \& I. Stone (Eds.) Polar Essays of the Arctic (pp. 123-140).Ushuaia: Editorial Fuegia,

Hacquebord, L. (2010). English and Dutch whaling stations in Spitsbergen (Svalbard) in the 17th Century. In J. E. Ringstad (Ed.) Whaling and History III (pp. 59-68). Sandefjord: Kommandør Chr. Christensens Hvalfangst Museum.

Hart, I. (2001). Pesca. The history of the Compañia Argentina de Pesca, Sociedad Anónima, of Buenos Aires. Salcombe: Aidan Ellis Publishing.

Hart, I. (2006). Whaling in the Falkland Island Dependencies 1904-1931. A History of shore and bay-based whaling in the Antarctic. Herefordshire: Pequena.

Indus (1938). La industria ballenera. Valparaíso: Compañía Industrial S.A.

Indus, 1951. 50 años al servicio del país. Valparaíso: Compañía Industrial S.A. 
Lawrence, S. \& M. Staniforth (Eds.) (1998). The Archaeology of Whaling in Southern Australia. Gundaroo, NSW: Brolga Press for the Australasian Society for Historical Archaeology and the Australian Institute for Maritime Archaeology.

Lennartsson, R. (2011). Notes on 'not being there'. Ethnographic Excursions in Eighteenth-Century Stockholm. Ethnologia Europea/Journal of European Ethnology, 41 (1), 105-116.

Lennartsson, R. (2012). Archival Ethnography: reflections on a Lost Note. Historisches Forum 14, 77-92

Lloyd's Register (1924). Lloyd's Register of British \& Foreign Shipping. London: Lloyd's Register.

Martinic, M. (1973). Actividad lobera y ballenera en Magallanes y Antártica, 1868-1916. Revista de Estudios del Pacífico, 7, 7-26.

Martinic, M. (1977). Antecedentes históricos sobre la caza de cetáceos en Chile. Anales del Instituto de la Patagonia, 8, 313-315.

Martinic, M. (2004). Antecedentes históricos sobre la caza de cetáceos en Chile. Boletín Antártico Chileno, 23(1), 7-12.

McGonogle, M. \& Staniforth, M. (2007). Balaena: A 20th Century Norwegian Whaling Station. In M. Staniforth \& M. McGonogle (Eds.) The Gaultois and Balaena Shore-Based Whaling Stations in Newfoundland, Canada. (pp. 23-32) Adelaide: Flinders University Maritime Archaeology Monographs Series.

Mcllroy, J. (1986). Bathers Bay Whaling Station, Fremantle, Western Australia. Australian Historical Archaeology, 4, 43-50.

Moulian, I. \& Lema, C. (2013). Breves visuales del patrimonio en Isla Guafo. Primer Informe. Dirección de Extensión de la Universidad Austral de Chile, Valdivia (manuscrito).

Navarro, M. (2008). Comunidades humanas y poblaciones de grandes ballenas: una aproximación desde la antropología al patrimonio natural y cultural de las localidades del archipiélago de los Chonos, Región de Aysén. Tesis para optar al Título de Antropóloga y el Grado de Licenciada en Antropología. Universidad Austral de Valdivia.

Nicholls, N. (2010). La Sociedad Ballenera de Magallanes: de cazadores de ballenas a héroes que marcaron la soberanía nacional. Historia (Santiago), 43, 41-78.

O'Dell, T. \& Willim. R. (2011). Irregular Ethnographies: An Introduction. Ethnologia Europea, 41 (1), 5-14.

Pastene, L.A. \& Quiroz, D. (2010). Outline of the History of Whaling in Chile. In International Center for Folk Culture Studies (Eds.). Human Culture from the
Perspective of Traditional Maritime Communities, International Symposium Report No. 1 (pp. 73-98). Kanagawa: Kanagawa Shimbun Press.

Patterson, A. (2006). The Sleaford Bay Tryworks: Industrial Archaeology of Shore Based Whaling Stations. Adelaide: The Flinders University of South Australia.

Pearson, M. (1985). Shore-Based Whaling at Twofold Bay: One Hundred Years of Enterprise. Journal of the Royal Australian Historical Society 71(1), 3-27.

Pereira Salas, E. (1971). Los primeros contactos entre Chile y los Estados Unidos, 1778-1809. Santiago: Andrés Bello.

Pricket, N. (2002). The archaeology of New Zealand shore whaling. Wellington: New Zesland Department of Conservation.

Quiroz, D. (2010a). Breve crónica de la cacería de ballenas en la zona de Valdivia (1906-1936). Revista Austral de Ciencias Sociales, 19, 75-98.

Quiroz, D. (2010b). La caza de ballenas en las aguas de Chiloé durante los siglos XIX y XX. Consultado en http://www.dibam.cl/Recursos/Contenidos/ DeAncud/archivos/la caza de ballenas en las aguas de Chiloé. pdf.

Quiroz, D. (2011). La flota de la Sociedad Ballenera de Magallanes: historias y operaciones en los mares australes (1905-1916). Magallania, 39(1), 33-58.

Quiroz, D. \& De la Fuente: (2012). Operaciones balleneras de la INDUS en aguas Patagónicas: años iniciales (19361939). Magallania, 40(2), 23-40.

Reeves, R.R. \& Smith, T.D. (2006). A taxonomy of world whaling: operations, eras, and data sources. In J.A. Estes, D.P. DeMaster, D.F. Doak, T.M. Williams y R.L. Brownell, Jr. (Eds.) Whales, whaling and ecosystems (pp. 82-101). Berkeley: University of California Press.

Reyes-Arriagada, R., Campos-Ellwanger: \& Schlatter, R. (2009). Aavifauna de Isla Huafo. Boletin Chileno de Ornitología, 15(1), 35-43.

Risting, S. (1922). Av Hvalfangstens Historie. Kristiania (Oslo): J.W. Cappelens Forlag.

Sepulveda, J. (2008). La epopeya de la industria ballenera chilena. Trece empresas balleneras chilenas. Boletín de la Academia de Historia Naval y Marítima de Chile, 11, 11-35.

Scott, W. F. V. (Ed.) (1927). Report on the industrial and economic situation in Chile. London: Department of Overseas Trade.

Sociedad Ballenera de Corral (1931) Undécima Memoria y Balance al 31 de octubre de 1931 de la Sociedad Ballenera de Corral, Valdivia. Valdivia: Imprenta 
Central.

Stanbury, M. (1985). Norwegian bay whaling station: an archaeological report. Perth: Western Australia Maritime Museum.

Swett, R. (1923) Guía Marítima de Chile, 1923-24. Valparaíso: Imprenta Victoria.

Tønnesen, J.N. \& Johnsen, A.O. (1982). The History of Modern Whaling. Berkeley \& Los Angeles: University of California Press.

Wietschorke, J. (2010). Historische Ethnografie. Möglichkeiten und Grenzen eines Konzepts. Zeitschrift für Volkskunde, 106, 197-223.

Wilson, T.L. (2012) Coming to Terms with History: Translating and Negotiating the Ethnographic Self. Historisches Forum 14, 5-21.

Diarios

Diario Oficial [Santiago, Chile], 1913-1936.

El Correo de Valdivia [Valdivia, Chile], 1913-1936.

La Cruz del Sur [Ancud, Chile], 1920-1936.

Inéditos

Decretos (1905-1936), Fondo Ministerio de Hacienda, Archivo de la Administración del Archivo Nacional [Santiago, Chile].

Escrituras Públicas de Santiago [Pedro N. Cruz, Nicolás Fabres], 1921-1925, Archivo de la Administración del Archivo Nacional [Santiago, Chile].

Escrituras Públicas de Valdivia, 1905-1936, Archivo del Conservador de Bienes Raíces de Valdivia [Valdivia, Chile]
Registro de Comercio de Valparaíso (1921), Archivo de la Administración del Archivo Nacional [Santiago, Chile].

Registro de Propiedades de Valdivia (1905-1936) Archivo del Conservador de Bienes Raíces de Valdivia [Valdivia, Chile]

Registro de Sociedades de Valdivia (1905-1936) Archivo del Conservador de Bienes Raíces de Valdivia [Valdivia, Chile]

\section{Entrevistas}

Raúl Pavié, Caleta Amargos [Valdivia], 15 de noviembre de 2008.

Onofre Almonacid, Quellón [Chiloé], 22 de noviembre de 2008.

Bernardino Bórquez, Quellón [Chiloé, 21 de noviembre 2008.

Juan Vera, Quellón [Chiloé], 23 de noviembre 2008.

Pedro Vera, Puerto Montt, 4 de diciembre de 2008.

Eduvino Cárcamo, Quellón [Chiloé], 28 de noviembre de 2008

Ricardo Saldivia, Quellón [Chiloé], 25 de noviembre de 2008.

Isaías Jaramillo Elgueta, Quilpué, 22 de febrero de 2010 .

Guillermo Lobos, Quellón [Chiloé], 22 de noviembre de 2008.

Ricardo Saldivia, Quellón [Chiloé], 25 de noviembre de 2008.

José Barrios, Quintay [Valparaíso], 20 de enero de 2010 . 
